\title{
Understanding Computational Methods for Solar Envelopes Based on Design Parameters, Tools, and Case Studies: A Review
}

\author{
Miktha Farid Alkadri ${ }^{1, *}$, Francesco De Luca ${ }^{2} \mathbb{B}$, Michela Turrin ${ }^{1}\left(\mathbb{C}\right.$ and Sevil Sariyildiz ${ }^{1}$ \\ 1 Department of Architecture and Engineering Technology, Faculty of Architecture and the Built Environment, \\ Delft University of Technology, Julianalaan 134, 2628 BL Delft, The Netherlands; M.Turrin@tudelft.nl (M.T.); \\ I.S.Sariyildiz@tudelft.nl (S.S.) \\ 2 Department of Civil Engineering and Architecture, Tallinn University of Technology, Ehitajate tee 5, \\ 19086 Tallinn, Estonia; francesco.deluca@taltech.ee \\ * Correspondence: M.F.Alkadri@tudelft.nl
}

Received: 27 April 2020; Accepted: 23 June 2020; Published: 28 June 2020

\begin{abstract}
The increasing population density in urban areas simultaneously impacts the trend of energy consumption in building sectors and the urban heat island (UHI) effects of urban infrastructure. Accordingly, passive design strategies to create sustainable buildings play a major role in addressing these issues, while solar envelopes prove to be a relevant concept that specifically considers the environmental performance aspects of a proposed building given their local contexts. As significant advances have been made over the past decades regarding the development and implementation of computational solar envelopes, this study presents a comprehensive review of solar envelopes while specifically taking into account design parameters, digital tools, and the implementation of case studies in various contextual settings. This extensive review is conducted in several stages. First, an investigation of the scope and procedural steps of the review is conducted to frame the boundary of the topic to be analyzed within the conceptual framework of solar envelopes. Second, comparative analyses between categorized design methods in parallel with a database of design parameters are conducted, followed by an in-depth discussion of the criteria for the digital tools and case studies extracted from the selected references. Third, knowledge gaps are identified, and the future development of solar envelopes is discussed to complete the review. This study ultimately provides an inclusive understanding for designers and architects regarding the progressive methods of the development of solar envelopes during the conceptual design stage.
\end{abstract}

Keywords: solar envelopes; passive design strategies; computational design methods

\section{Introduction}

The United Nations (UN) estimates that by 2050 the world's population in urban areas will increase by approximately $68 \%$ [1], with urban dwellers being around 6.7 billion [2]. This trend is simultaneously followed by a continuous increase in energy consumption from the building sector, which will account for $1.3 \%$ of the annual increment and reach $22 \%$ in 2050 [3]. This means that a future urban planning requires sustainable strategies to deal with energy use and building emissions [4]. Some strategies have been proposed to tackle these issues using nationally determined contributions (NDCs) and the UN sustainable development goal (SDG) programs. For example, many researchers have actively developed specific methods and tools to provide more practical guidance regarding sustainable buildings and construction technologies, such as the adoption of green building technologies [5,6] and the enhancement of building energy efficiency $[7,8]$. However, past surveys did not discuss the conceptual domain of passive design strategies but rather focused predominantly on the 
technical building operations such as heating, ventilation, and air conditioning (HVAC) systems $[9,10]$. Consequently, a knowledge gap exists when addressing the environmental performance of building designs, especially at the conceptual design stage. This paper contributes by increasing the knowledge on passive design strategies. Specifically, it comprehensively reviews and examines computational methods, parameters, tools, and case studies related to solar envelopes.

This review is relevant in that it addresses a contextual design approach in which solar envelopes play a significant role in enhancing the quality of the built environment. Furthermore, this review integrates the environmental performance of a new building with the existing context and contributes to the most crucial design decisions made during the early design phase. In this respect, the concept of solar envelopes has made a relevant contribution by addressing the solar accessibility of new buildings and their existing contexts. By definition, solar envelopes are composed of the maximum volumetric container as determined by the amount of desirable or required sun access without considering the shadowing of adjacent buildings [6]. Accordingly, the envelope of proposed designs can be maximized without compromising the solar rights of surrounding buildings during the critical period. During the conceptual design process, this concept is useful for architects, as they seek to avert potential failures once a new building has been constructed, especially with respect to negative microclimatic impacts. In design practices, this approach has successfully been implemented by the Dutch architectural and urban design firm MVRDV through the project of P15 Ravel Plot, which is located in the Zuidas district, 1082 LC, Amsterdam [11] and the Grotius Tower II, which is located in the area of the Prince Bernard Viaduct, Den Haag [12]. These projects have similarly addressed the idea of solar-oriented design by integrating the optimal sightline for each housing unit with the terraces and greenery landscape. In so doing, proposed buildings have successfully presented high performing envelopes that fulfil both geometric and environmental performance quality.

Since the inception of the solar envelope, several methods for its determination have been developed. For example, Topaloglu [13] describes three simple techniques for establishing solar envelope, namely, the descriptive, profile angle, and 2D orthographic projection techniques. The descriptive technique adopts the initial solar envelopes concept introduced by Knowles [14]. As such, it intersects the vertical planes plotted on the selected site by using the trigonometric principles of the solar azimuth $(\theta)$, altitude $(\alpha)$ and, cut-off times (i.e., daily and annual time limits). For example, given a full day setting, the morning sun governs the envelope's boundary of its western limits, while the afternoon sun establishes the envelope's shape of its eastern limits. This same mechanism applies to the annual time setting by calculating the sun's position during the winter and summer months. The profile angle technique consists of an intersection between inclined planes that are generated on each edge of the plot according to minimum solar angles as determined by a different orientation. In general, the profile angle is also employed to determine the geometric positions of the shading devices, the penetration of the sun's rays into a room, and the shading line on the building's facades. The orthographic projection technique employs a mechanism similar to that of the profile angle techniques but only applies to rectangular sites with two elevation planes within a two-dimensional projection. While these methods are valuable and convenient, further consideration of several aspects is required including the simulation time, range of input parameters, and accuracy of the 3D visualization, especially with respect to complex architectural forms [15]. In contrast to the above, this review investigates computational methods that offer several effective ways to address these challenges. Hence, ultimately, this study advances the work on the sustainable design approach by providing an overview on the current state of the computational environment of solar envelopes and exposing critical gaps for future consideration.

Having introduced the relevance and basic principles of solar envelopes, this paper is organized as follows: Section 2 describes the scope and procedure of the review, and Section 3 presents the results of the review and discusses the computational design methods for solar envelopes and related design parameters are presented. For each design method described in Section 3, Section 4 focuses on the aspects of the computational environment in parallel with the digital tools and the implementation of 
the case studies. Section 5 then addresses the knowledge gaps and new directions for future research on solar envelopes, and Section 6 presents the conclusions.

\section{Scope and Method of the Review}

This review addresses the main question that frames the survey of existing computational solar envelopes, i.e., What are the performance criteria and related computational methods for generating solar envelopes? This question simultaneously leads us to explore specific tasks and features of various design parameters, tools, and the implementation of case studies found in each design method of solar envelopes. The ultimate goals are to identify and understand the most basic and advanced parameters and computational methods for constructing solar envelopes and to analyze relevant factors that affect the complexity and flexibility of solar envelope methods from the perspective of the user. Explicit awareness of these issues is crucial for the comprehensive understanding of the current use of solar envelopes and to address the design needs and method gaps with respect to solar envelopes.

The articles for review are accessed through three selected literature databases, namely, Web of Science (WoS), Scopus, and Google Scholar (GS). Although there are many database searches that can be used for a literature review, this study focuses on employing Scopus, WoS, and GS because they are part of a wide citation and bibliographic searching platform that have been designed to support scientific and research environment globally. To be more specific, Scopus and WoS similarly present substantial factual information that includes a number of peer-reviewed literature and article indexed through the Elsevier and ISI citation databases, respectively. On the other hand, GS has also been extensively utilized for a large interdisciplinary field coverage with a wide unique type of materials (i.e., PDF files, Word docs, and technical reports), including indexed and non-indexed articles, especially for Master and $\mathrm{PhD}$ theses that contain relevant information for the topic of solar envelopes [16,17]. Accordingly, it can complement other databases such as Scopus and WoS that are predominantly based on indexed publications.

Furthermore, a new direction for the further development of solar envelopes is identified as a result of this review, which considers three main topics and sub-topics, namely, conceptual themes (i.e., solar architecture, solar envelopes, and solar access), design workflow (i.e., computational design, solar design, and solar simulation), and contextual settings (urban planning, urban design, and architectural design). The scientific findings of the reference databases are narrowed by setting the timespan to range between 1960 and 2019, given that the term "solar envelopes" was initially introduced in the scientific literature by Knowles around 1970 [18] although some authors, such as Giacomo [19], Galton [20], and Atkinson [21] implicitly discussed related topics regarding solar access prior to Knowles' work. The detailed parameters used for reference databases are shown in Table A1 in Appendix A.

Given that the resulting search remains extremely broad, the screening process is then weighted on references that only investigate the concept of solar envelopes within the domain of passive design strategy. To do so, some irrelevant references resulting from a discrepancy in research objectives are eliminated. For example, studies related to solar-form finding that focuses only on a generative architectural form [22-24], solar performance simulation that merely addresses the quantification of solar energy for existing building facades, 2D plans and new development areas [25-27], and studies related to solar radiation analysis that examine solar potential for the urban contexts $[28,29]$. These references are consequently not further included in the main discussion of the review. In addition, this study identifies one previous review of solar envelope properties authored by Stasinopoulos [30]. However, this recent study focuses on the construction of solar envelopes based on solid modeling techniques [31], an area that can benefit from further consideration in our review that systematically addresses: (1) a comprehensive study of computational solar envelopes based on various methods, tools, and contextual settings of various case studies, (2) an in-depth investigation of design parameters that correspond to different computational methods and the identification of relevant parameters for each method, and (3) several criteria that enable the further analysis of current gaps and future directions of the study. Therefore, the present review can be a very useful companion to the researchers 
involved in studying new methods and computational tools for generating solar envelopes. Due to the presented potentialities of solar envelopes, the expected impact of this review at large, is that to help in developing new design tools to increase sustainability, resource efficiency, and livability of our buildings and cities.

After having selected the relevant references that meet the screening criteria, this study proposes a conceptual framework for the review as presented in Figure 1.

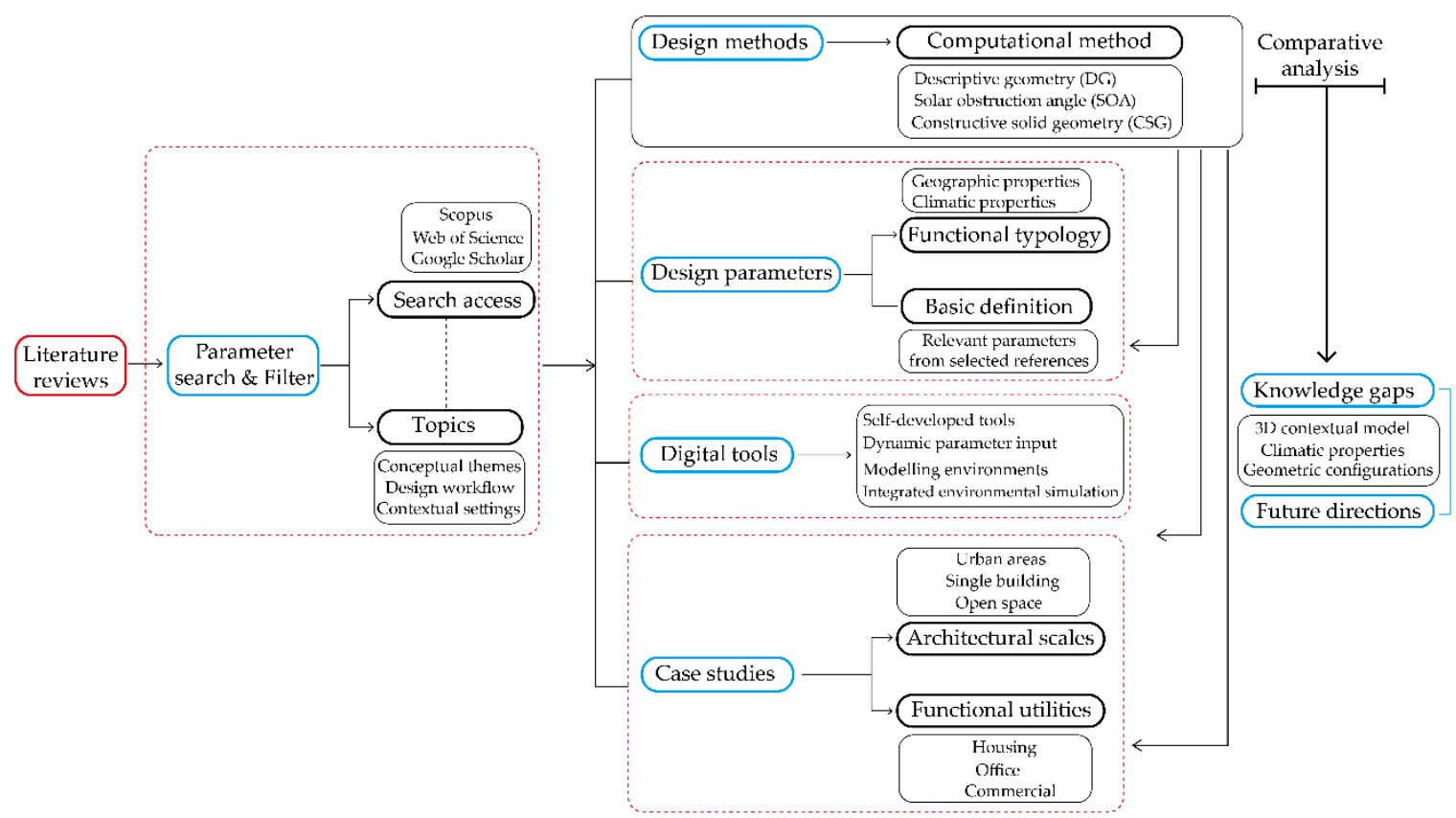

Figure 1. General framework of the review.

\section{Review Findings: Computational Methods and Parameters of Solar Envelopes}

This section presents the results of the review by investigating the computational methods and the parameters for solar envelopes obtained from the 58 selected references. The computational methods based on design procedures when establishing solar envelopes are first categorized. This is followed by extracting and mapping the parameters from the selected references into the database and then, drawing a comparative analysis among the methods and parameters based on their frequency of use. These actions facilitate the identification of additional characteristics of the parameters and the performance aspects of each design method.

\subsection{Design Methods}

By examining the basic computational procedures of each collected reference, this study identifies three methods of computational solar envelopes, namely, descriptive geometry (DG), solar obstruction angle (SOA), and constructive solid geometry (CSG).

- Descriptive geometry (DG)

As a derivative approach from the descriptive mechanism, the DG method employs basic parameters such as latitude, a closed boundary of selected site, Sun vectors, cut-off-times, and obstruction geometry of surrounding buildings, to generate solar envelopes. However, the use of these parameters is highly dependent on the type and objective of the projects. When simulating, for example, no-obstruction solar envelopes, such as parks and open spaces, the relevant parameters only require a closed curve of the site, the latitude and/or sun vectors, and the maximum height of the intended envelope given that the aim is to maximize solar access of the proposed envelope within a specific period. Moreover, solar envelopes that incorporate the surrounding context must consider 
the geometric obstacles from the existing context. This is pertinent when developing solar rights and solar collection, as the proposed envelopes cannot violate the solar access of neighboring buildings (solar rights) and the surrounding buildings cannot obstruct the sun access of the proposed envelopes (solar collection) [32].

- Solar obstruction angle (SOA)

The SOA method simulates the projection of the minimum profile angle on each side of the plot through shadow lines and shadow angles. In this approach, the reference lines refer to the horizontal property lines of the north and the vertical axis, i.e., where the existing building stands in relation to the Cartesian space [33]. Due to daylight and the different orientation on each side of the plot, the resulting geometry of the SOA varies. Higher settings regarding the angle of solar obstruction produce shorter periods of shading and minimum shading conditions. Therefore, each side of the plot should be treated differently because of the shading conditions unique to each side. For example, it is important to minimize solar obstruction in designated areas within a range of $\pm 30^{\circ}$ for southern facades due to passive solar gains while taking into account latitude position in the UK [24].

- Constructive solid geometry (CSG)

The CSG method refers to a solid modeling approach [31] based on the Boolean operations of subtraction and intersection between the 3D plot and the initial shapes of new buildings. These initial shapes are usually generated from two settings of solar vectors. For example, the first solar vector, which may correspond to a solar access constraint or Sun position is calculated by using latitude, longitude, and cut-off times. Furthermore, the second solar vector refers to the vectors that are generated from the Sun path diagram [34]. In principle, these settings can be used in either a full [35-37] or a partial way $[38,39]$ during the construction of solar envelopes depending on the design concept and the complexity of the surrounding contexts. The CSG method can also be complemented with a solar fan to adjust the height and width of the floors of surrounding buildings.

In general, these computational methods have successfully addressed various advanced simulation techniques for establishing solar envelopes. However, these same methods also create dissimilar computational behaviors during the construction of solar envelopes. For example, among the three methods, CSG exhibits the highest rate of generating an unpredictable model in terms of the final configuration of geometric solar envelopes. This is because the CSG method primarily involves the volumetric intersection between different shapes, which means that the probability of yielding unstructured envelopes is also moderately high. Furthermore, but consistent with this, the geometric configuration of CSG requires a high computational performance, especially with respect to the mesh modeling of the contoured plot in larger urban scales. In contrast to the CSG method, however, the DG and SOA methods establish solar envelopes based on the plane intersections that are generated from shadow fences or the obstacle curves of surrounding buildings. Accordingly, solar envelopes that are constructed based on DG and SOA are not generally computationally intensive.

To better understand the characteristics of each computational method when considering the design practices, it is also important to examine the specific elements relevant during the simulation process, such as the basic and advanced parameters of each method, the interrelations between design parameters, and the contextual settings of each method of each specific project. The following section will discuss these aspects based on the collected references.

\subsection{Design Parameters}

Design parameters include various aspects that determine the geometric and spatial properties of solar envelopes during the simulation process. Hence, this section focuses primarily on identifying each type of parameter included in the selected references. According to its functional typologies on space-time constraints [14], this study further subdivides the parameters into geographic and climatic properties. Geographic properties include a series of elements that constitute a spatial relationship between 
a selected plot and the surrounding environment whereas climatic properties refer to the non-geometric characteristics that are primarily considered when establishing the time for the construction of the geometric model of the solar envelopes. In total, this study identifies 18 parameters from the collected references; among these parameters, 11 are regarded as geographic properties (i.e., longitude, latitude, orientation, courtyard, surrounding facades, sidewalk, surrounding building's height, floor area ratio (FAR), setback, shadow fences, and street), and seven are regarded as climatic properties (i.e., profile angle, cut-off times, dry bulb temperature, sun path, solar azimuth, solar altitude, and sun access duration). Similar to space and time, these properties also involve an inverse construction mechanism when assessing the volumetric size of solar envelopes. For example, the greater the time interval (cut-off-time) of the solar envelopes, the less the space that is produced inside the envelope. Similarly, the more sun access duration there are, the less the volume of the constructed solar envelope. Regarding the site orientation, the long sides of building with an in east-west (EW) orientation are larger and have higher ridges in the geometric envelopes than the long-sided areas with a north-south (NS) orientation. In contrast, the widths of streets and courtyards on the EW sides generate the minimum height for solar envelopes [39].

To draw an in-depth analysis among parameters and methods of solar envelopes, it is necessary to examine the distribution level of each parameter for each corresponding method with respect to quantity and priority.

\subsection{Comparative Analysis of Design Parameters in Relation to Design Methods}

This comprehensive analysis between the design parameters and computational methods of solar envelopes consists of three major tasks. First, each parameter and its corresponding references based on computational methods must be plotted (see Figure 2) to provide an overview of the distribution pattern regarding the method and the total number of references of each parameter. Second, the usage frequency between parameters and their corresponding methods must be plotted (see Figure 3). This facilitates the categorization of the parameters into three different groups, namely, high, medium, and low, according to their usage level during the construction of the solar envelopes. Third, the total number of parameters, i.e., geographic and climatic properties, registered for each computational methods are calculated based on the predefined categories discussed (see Figure 4). This allows us to identify the most basic and the most advanced parameters as well as the methods used to establish solar envelopes.

Table 1. Database of design parameters and computational method of solar envelopes based on the selected references.

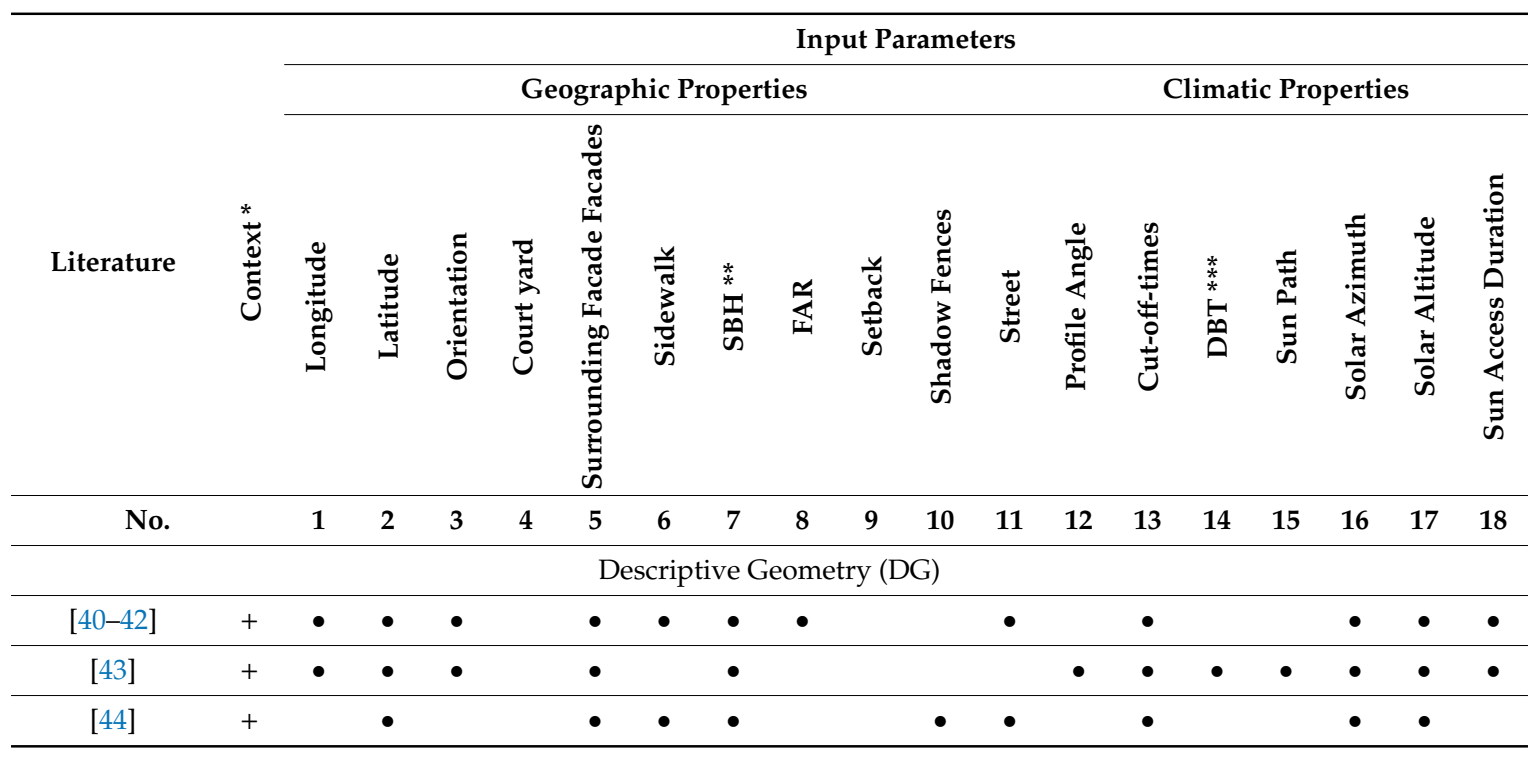


Table 1. Cont.

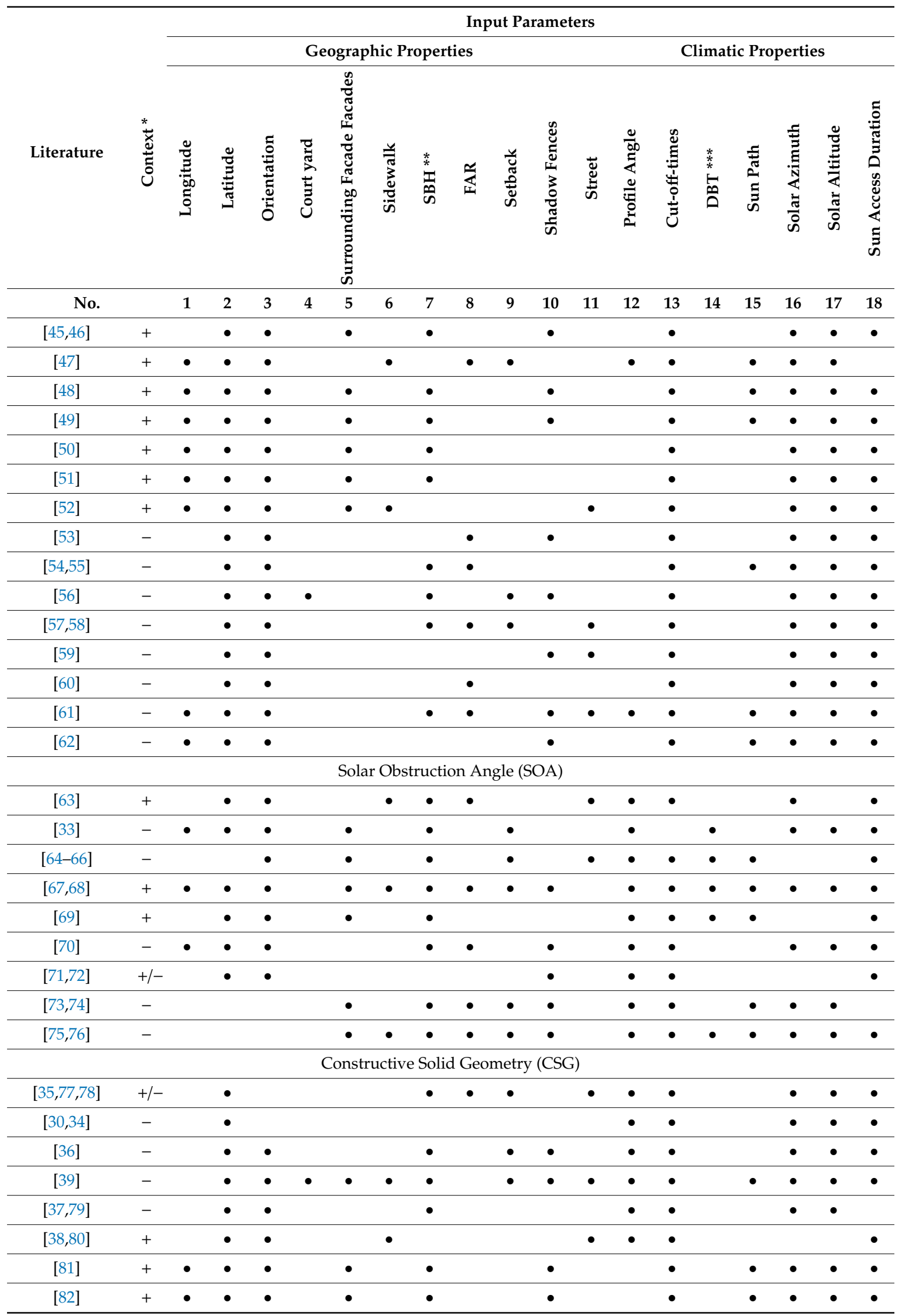


Table 1. Cont.

\begin{tabular}{|c|c|c|c|c|c|c|c|c|c|c|c|c|c|c|c|c|c|c|c|}
\hline \multirow[b]{3}{*}{ Literature } & & \multicolumn{18}{|c|}{ Input Parameters } \\
\hline & & \multicolumn{11}{|c|}{ Geographic Properties } & \multicolumn{7}{|c|}{ Climatic Properties } \\
\hline & 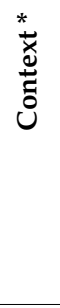 & 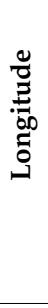 & 莺 & 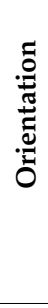 & 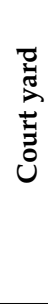 & 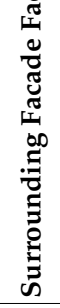 & 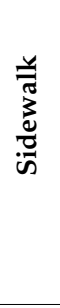 & $\begin{array}{l}\stackrel{*}{*} \\
\text { 呄 } \\
\text { जै }\end{array}$ & $\underset{x}{\mathbb{x}}$ & 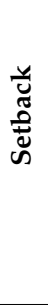 & 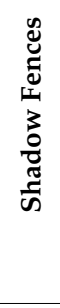 & $\begin{array}{l}\text { एँ } \\
\text { के }\end{array}$ & 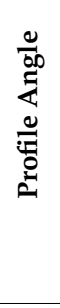 & 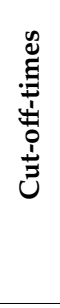 & 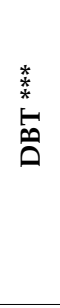 & 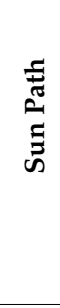 & 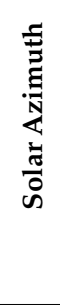 & 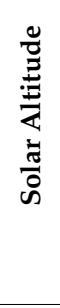 & 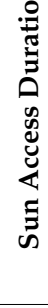 \\
\hline No. & & 1 & 2 & 3 & 4 & 5 & 6 & 7 & 8 & 9 & 10 & 11 & 12 & 13 & 14 & 15 & 16 & 17 & 18 \\
\hline [83] & + & $\bullet$ & $\bullet$ & $\bullet$ & & $\bullet$ & & $\bullet$ & & & $\bullet$ & & & $\bullet$ & & $\bullet$ & $\bullet$ & $\bullet$ & $\bullet$ \\
\hline$[84,85]$ & + & $\bullet$ & $\bullet$ & $\bullet$ & & $\bullet$ & & $\bullet$ & & & $\bullet$ & $\bullet$ & $\bullet$ & $\bullet$ & & & $\bullet$ & $\bullet$ & $\bullet$ \\
\hline$[15,86]$ & + & & $\bullet$ & $\bullet$ & & $\bullet$ & & $\bullet$ & & & $\bullet$ & $\bullet$ & $\bullet$ & $\bullet$ & & $\bullet$ & $\bullet$ & $\bullet$ & $\bullet$ \\
\hline [87] & - & & $\bullet$ & $\bullet$ & & & & & & & $\bullet$ & & & $\bullet$ & & $\bullet$ & $\bullet$ & $\bullet$ & $\bullet$ \\
\hline [88] & + & $\bullet$ & $\bullet$ & $\bullet$ & $\bullet$ & $\bullet$ & & & & • & & & & - & & $\bullet$ & • & • & • \\
\hline
\end{tabular}

${ }^{*}$ Context $=(+)$ include site properties, $(-)$ exclude site properties; ${ }^{* *}$ S.B.H $=$ Surrounding building's height; ${ }^{* * *}$ D.B.T = Dry Bulb Temperature.

To perform these three tasks, Table 1 provides the necessary preliminary information regarding the distribution of design parameters and corresponding methods based on the selected references.

Table 1 displays a list of the selected references on computational solar envelopes that are plotted based on their design methods. Each of these references is then further investigated by marking its contextual settings and parameters through a binary operation. For example, the "True" condition is indicated with a bullet point, whereas the "False" condition remains empty. The results illustrate that some references nearly fulfill all of the listed parameters (e.g., $[39,67,68]$ ), while others require only six parameters $([30,34,71,72])$ to construct solar envelopes.

This is because each reference is affected not only by the type of applied computational method but also by the design concept of the projects that often involve more parameters. With respect to the contextual settings, the plot condition for solar envelopes is divided into the inclusion and exclusion conditions of surrounding site properties (e.g., vegetation, adjacent buildings, open spaces, and other relevant elements). Accordingly, the solar envelope simulations that include site properties create spatial negotiations between the proposed building and the existing context, while the exclusion condition focuses on the given land parcel, and hence, the context implementations primarily correspond to new development areas. In general, all categorized methods contain both inclusion and exclusion conditions during the construction of solar envelopes.

As the most-used method, DG considers site properties more often than SOA and CSG. However, the DG method cannot guarantee the number of involved parameters during the simulation because the input parameters of solar envelopes rely on design concept and project complexity. For example, Camporeale [58] and Saleh and Al-Hagla [55] employ more variations of design parameters than with Machacova et al. [44] and Martin and Keeffe [45], who take into account the surrounding site properties.

Having established the preliminary database regarding design parameters and solar envelope methods presented in Table 1, a comparative analysis of the two can now be performed.

- Task 1-Design parameters, methods, and total references

Figure 2 illustrates the pattern of computational solar envelopes based on the registered parameters and the number of references for each method. In general, the trend indicates that, with respect to using the parameters of solar envelopes, DG is referenced in more studies that the other two methods. Specifically, DG is referenced in 23 studies, followed by CSG with 20 and SOA with 15 . This provides 
an early indication that DG is the most-used technique for constructing solar envelopes. Additionally, DG includes four parameters, i.e., latitude, orientation, cut-off times, and solar altitudes, thus nearly satisfying all selected references, while SOA and CSG consist of one (profile angle) and two (latitude and cut-off times) parameters, respectively. Moreover, an interesting pattern is observed regarding parameters 4 (courtyard) and 14 (dry bulb temperature). Specifically, these parameters are similarly registered only in two methods for parameter 4, i.e., DG and CSG, and two methods for parameter 14, i.e., DG and SOA. Hence, it can be argued that courtyard and dry bulb temperature are rarely used parameters and are thus irrelevant properties for SOA and CSG, respectively. This condition also indicates the relevance of parameters that may only be employed in certain context during the construction of solar envelopes.

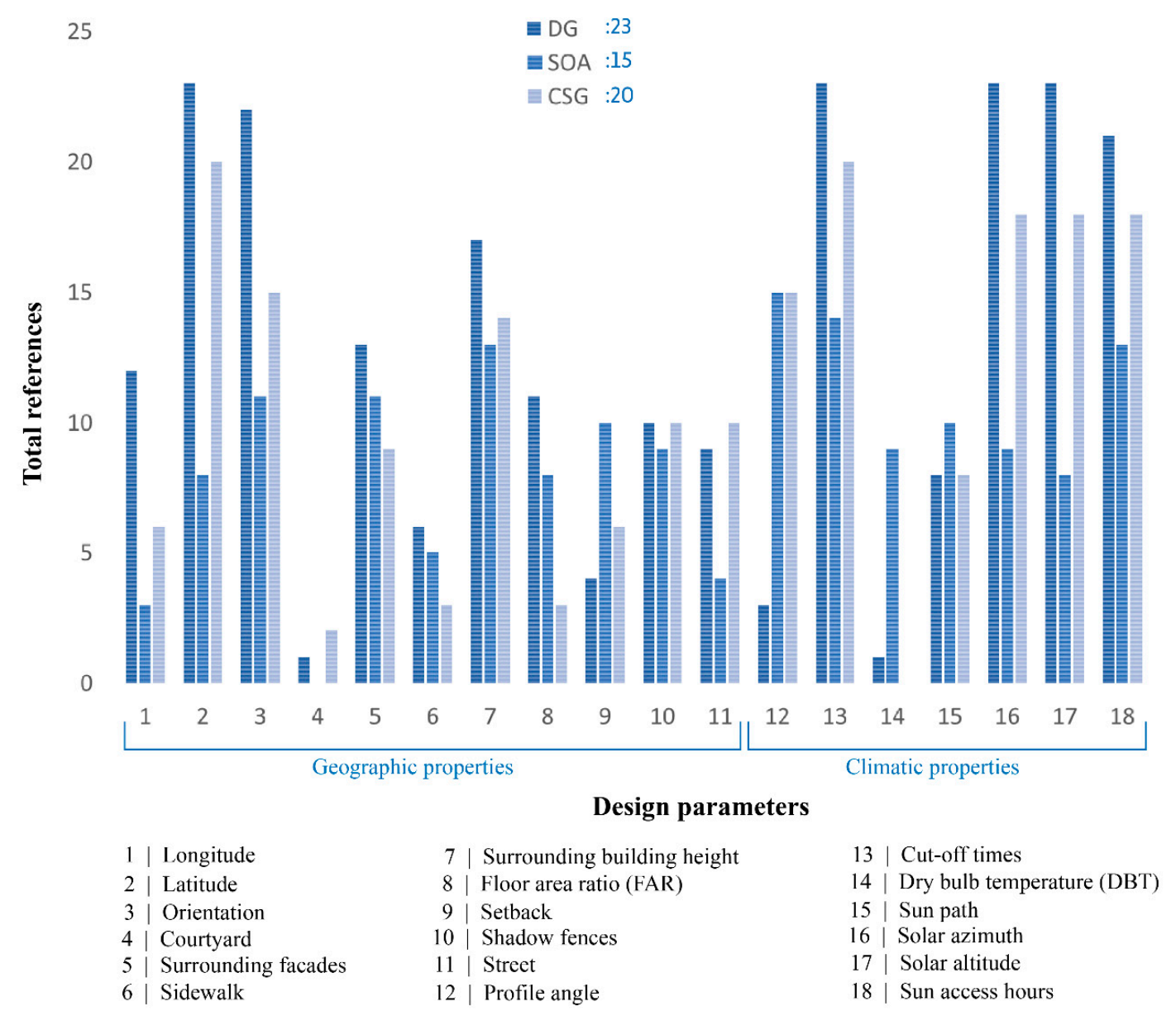

Figure 2. Distribution of design parameters according to corresponding computational methods and selected references.

- Task 2-Usage frequency of parameters and corresponding methods

After quantifying the total references for each parameter and corresponding method in Figure 2, the usage frequency of the parameters is divided by the total references for each method into three groups with each group comprising a certain range of references that indicates the usage frequency level of the parameters. Accordingly, the higher the number of references is for one parameter, the higher the frequency of that parameter's use during the construction of solar envelopes. For example, DG contains 23 references that correspond to 18 parameters. One parameter may consist of a different number of references depending on the type of parameters and how many studies that use that parameter. These 23 references are then divided into three range groups, whereby each group represents a different level of frequency; e.g., the high category consists of nine references, followed by the medium and 
low categories with eight and six references, respectively. To identify the category for each parameter, the specific ranges of total references for each category should be defined first. Specifically, the high category ranges from 15 to 23 references, while the medium and low categories range from seven to 14 and from one to six references, respectively. Hence, a specific category for each parameter can be identified and similar approach can now be applied to other methods.

As illustrated in Figure 3, the general trend reveals a fluctuating pattern in the percentages for each category of each method. For example, the greatest percentages for each category are identified by different methods. For example, the high category is fulfilled by CSG with $45 \%$, whereas SOA and DG dominate the medium and low categories with $45 \%$ and $33 \%$, respectively. These highest numbers simultaneously represent the priority usage of parameters when constructing solar envelopes, which means that the parameters listed within the high and medium categories serve as basic parameters for establishing solar envelopes. Moreover, the low category, due to its lowest usage values, especially for SOA and SCG is a list of the advanced and complementary parameters, and accordingly, only a few parameters can be used in this category such as longitude and street for SOA and courtyard, sidewalk, and FAR for CSG. An exception applies to DG because it contains more assigned parameters and references, i.e., nearly $18 \%$ above the other values. Based on these data, it is concluded that DG is the most-used method, as evidenced by its wide range of options for complementary parameters. Moreover, the small discrepancies in the values between each category in DG results in greater flexibility with respect to switching parameters when establishing solar envelopes.

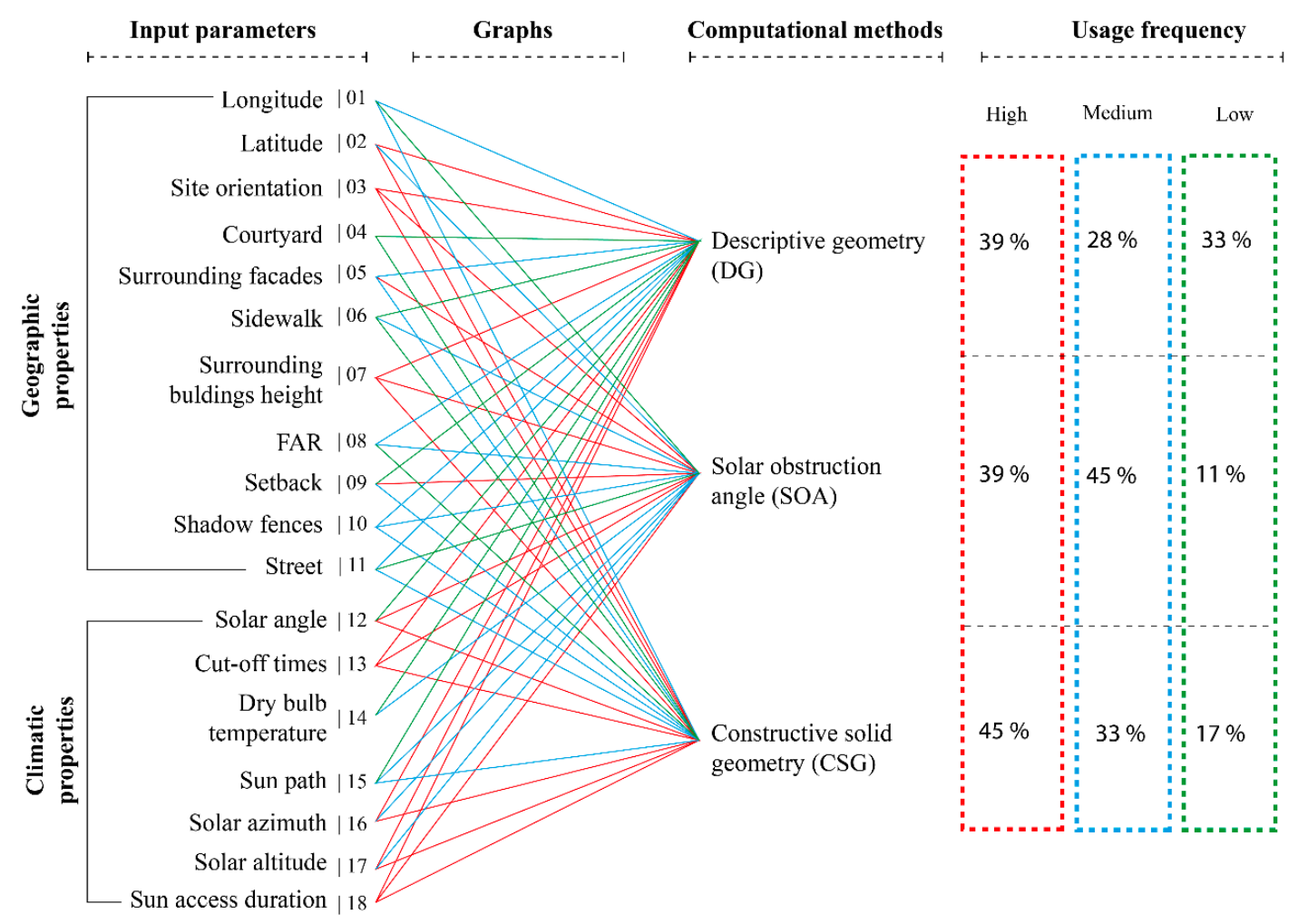

Figure 3. Categorization of design parameters and corresponding methods based on usage frequency.

- Task 3-Quantity of geographic and climatic parameters for each corresponding method

The plot of the parameters illustrated in Figure 4 requires further explanation. First, denoting the highest usage frequency, the high category confirms the greatest numbers of parameters that are incorporated in all methods. This category consists of four parameters (i.e., site orientation, surrounding building height, cut-off times, and sun access duration), whereas the remaining parameter, shadow fences, is found only in the medium category. Based on the similarity of the three methods, these shared parameters can be further defined as global parameters. However, there are several 
parameters, such as surrounding facades, set back, latitude, sidewalk, dry bulb temperature, solar azimuth, solar altitude, longitude, and street, that are included only in particular methods. As these parameters specifically correspond to SOA, they are defined as local parameters. To some extent, these local parameters act as basic parameters when they are located in the high-frequency use category (red dashed box) while at the same time, they are considered nonstandard parameters when implemented in other methods. For example, setback is a regular parameter for SOA, but it is regarded as an advanced or nonstandard parameter for DG. This is because SOA requires different daylight conditions on each side of the plot and is therefore influenced by the setback and plot orientation, whereas DG treats the same condition based on the whole boundary of the plot. Another interesting trend is the DG's local parameters (i.e., setback, solar angle, dry bulb temperature, and sun path), which simultaneously become advanced parameters because they are in the low-frequency use category. As a the most frequently used method, this trend indicates that DG exhibits a higher degree of complexity, especially when comparing the quantity of DG's local parameters to those of the other two methods. Thus, it is worth noting that the specific parameter of a solar envelope plays a great role in determining the computational workflow of the simulation method.

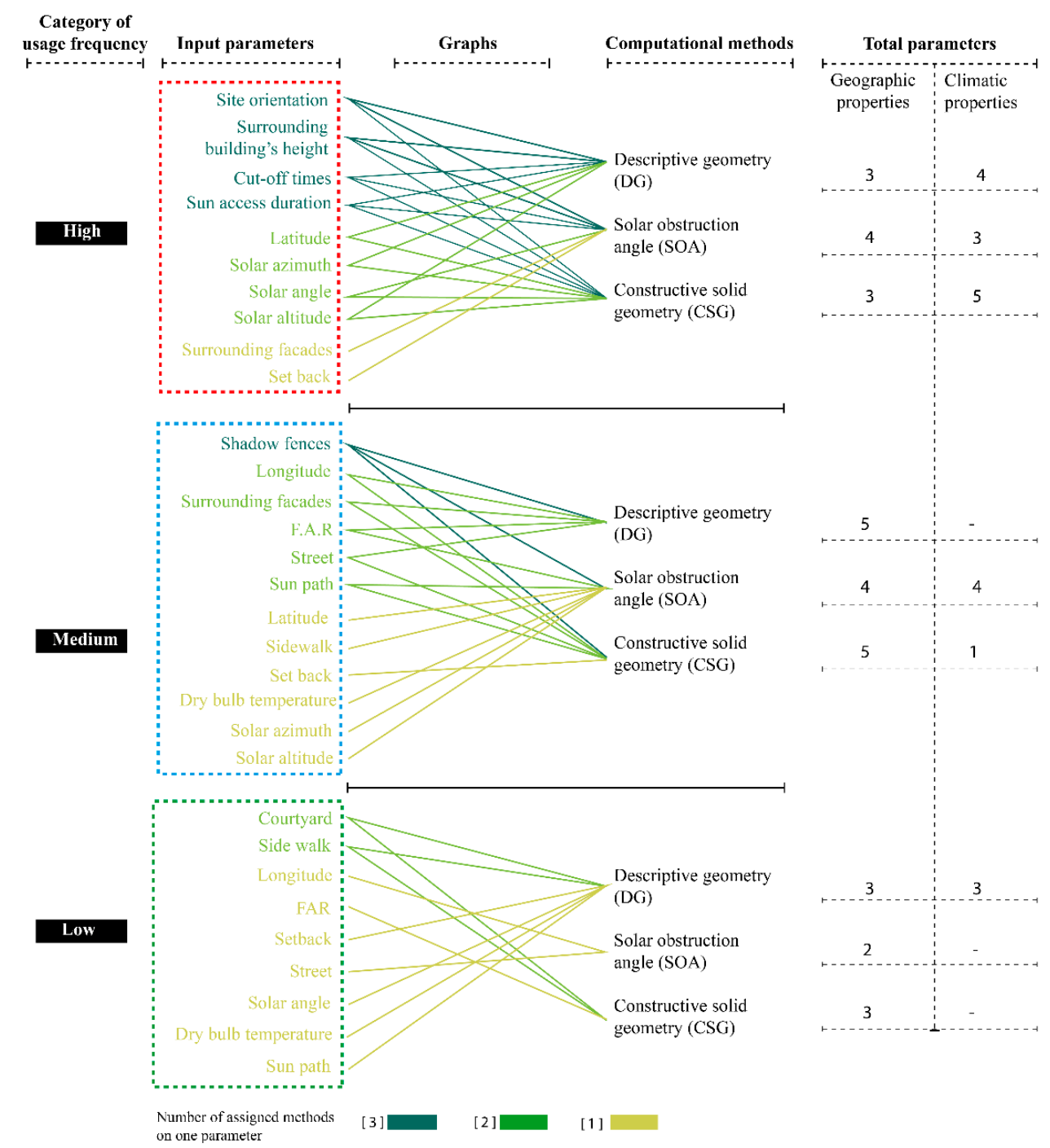

Figure 4. Specific distribution of design parameters (geographic and climatic properties) based on the group usage frequency and corresponding methods.

Second, after plotting the parameters based on the usage frequency, the number of geographic and climatic properties for each method can be determined. The general trend indicates that only the 
parameters from both categories are found in the high category while only parameters that satisfy the geographic properties are assigned to the other two methods. Specifically, climatic properties are absent from the medium (DG) and low categories (SOA and CSG). This is not only because the total number of assigned parameters in the high category is greater than that in the others but also because the medium and low categories are populated with rarely-used parameters.

\section{Discussion: Digital Simulation Tools and Case Studies}

An investigation of the computational environment of solar envelopes focuses on two qualities, namely, digital simulation tools and implementation of case studies (see Table 2), which are specifically investigated based on computational criteria and typologies of the projects, respectively. To conduct this investigation, each selected reference is evaluated by using a similar binary operation, as in the previous section, and the evaluation is conducted based on predefined computational parameters. For example, the digital tools of each selected reference are first investigated, and the evaluation criteria are then established based on four relevant factors i.e., self-developed tools, dynamic-parameter input, modeling environment, and integrated environmental simulation. The project implementations (case studies) are then specified according to two aspects, namely, architectural scales (i.e., urban, open space, and single building) and functional utilities (i.e., housing, offices, and commercial).

Table 2. Database of the computational environment parameters of solar envelopes based on the selected references.

\begin{tabular}{|c|c|c|c|c|c|c|c|c|c|c|c|c|c|c|}
\hline \multirow{4}{*}{ Literature } & \multirow{4}{*}{ Digital Tools } & & & & & \multicolumn{9}{|c|}{ Case Studies } \\
\hline & & \multirow{2}{*}{\multicolumn{4}{|c|}{ Computational Criteria }} & \multirow{2}{*}{\multicolumn{3}{|c|}{$\begin{array}{l}\text { Architectural } \\
\text { Scales }\end{array}$}} & \multirow{2}{*}{\multicolumn{6}{|c|}{ Functional Utilities }} \\
\hline & & & & & & & & & & & Hou & & & \\
\hline & & $\mathbf{A}$ & B & C & D & $\mathrm{E}$ & $\mathbf{F}$ & G & $\mathbf{H}$ & $\mathbf{I}$ & $\mathbf{J}$ & K & $\mathbf{L}$ & $\mathbf{M}$ \\
\hline \multicolumn{15}{|c|}{ Descriptive Geometry (DG) } \\
\hline [40-42] & SustArc & $\bullet$ & & $\bullet$ & $\bullet$ & $\bullet$ & & $\bullet$ & & & $\bullet$ & & & \\
\hline [43] & $\begin{array}{l}\text { Rhino, Grasshopper } \\
\text { (Ladybug) }\end{array}$ & & $\bullet$ & $\bullet$ & $\bullet$ & & & $\bullet$ & & & & $\bullet$ & $\bullet$ & \\
\hline [44] & - & & & $\bullet$ & & $\bullet$ & & $\bullet$ & & & $\bullet$ & $\bullet$ & & \\
\hline$[45,46]$ & CAD & & & $\bullet$ & & $\bullet$ & & $\bullet$ & & & & $\bullet$ & $\bullet$ & $\bullet$ \\
\hline [47] & - & & & & & & $\bullet$ & & & & & $\bullet$ & & \\
\hline [48] & $\begin{array}{l}\text { Rhino, Grasshopper } \\
\text { (Ladybug, Octopus) }\end{array}$ & & $\bullet$ & $\bullet$ & $\bullet$ & & & $\bullet$ & & $\bullet$ & & & & \\
\hline [49] & $\begin{array}{l}\text { Rhino, Grasshopper } \\
\text { (Ladybug) }\end{array}$ & & $\bullet$ & $\bullet$ & $\bullet$ & & & $\bullet$ & & $\bullet$ & & & & \\
\hline [50] & T4SU, Sketchup, GIS & $\bullet$ & $\bullet$ & $\bullet$ & & & & $\bullet$ & & & & & $\bullet$ & \\
\hline [51] & AutoCAD & & & $\bullet$ & & & & $\bullet$ & $\bullet$ & & & & $\bullet$ & $\bullet$ \\
\hline [52] & Heliodon, Ecotect & & $\bullet$ & $\bullet$ & $\bullet$ & $\bullet$ & & $\bullet$ & $\bullet$ & & & & $\bullet$ & • \\
\hline [53] & TAS (EDSL v. 9.09) & & $\bullet$ & $\bullet$ & $\bullet$ & & & $\bullet$ & & $\bullet$ & & & & \\
\hline$[54,55]$ & $\begin{array}{l}\text { Rhino, Grasshopper, Diva, } \\
\text { Ecotect, Vasari }\end{array}$ & & $\bullet$ & $\bullet$ & $\bullet$ & $\bullet$ & & & & & $\bullet$ & & & \\
\hline [56] & $\begin{array}{l}\text { CalcSolar (Autolisp)- } \\
\text { Autocad }\end{array}$ & $\bullet$ & & $\bullet$ & & & $\bullet$ & $\bullet$ & & & $\bullet$ & & & \\
\hline$[57,58]$ & $\begin{array}{l}\text { Rhino, Grasshopper, } \\
\text { Ecotect, Galapagos }\end{array}$ & & $\bullet$ & $\bullet$ & $\bullet$ & $\bullet$ & & & & & $\bullet$ & & & \\
\hline [59] & - & & & & $\bullet$ & $\bullet$ & & $\bullet$ & & $\bullet$ & & & & \\
\hline [60] & $\begin{array}{c}\text { AutoCAD, Sketchup, 3D } \\
\text { Max }\end{array}$ & & $\bullet$ & $\bullet$ & & & & $\bullet$ & $\bullet$ & & & & & \\
\hline [61] & - & & & & $\bullet$ & & $\bullet$ & $\bullet$ & $\bullet$ & & & & $\bullet$ & $\bullet$ \\
\hline [62] & Autodesk & & & • & & • & & & & & • & & & \\
\hline
\end{tabular}


Table 2. Cont.

\begin{tabular}{|c|c|c|c|c|c|c|c|c|c|c|c|c|c|c|}
\hline \multirow{4}{*}{ Literature } & \multirow{4}{*}{ Digital Tools } & \multirow{3}{*}{\multicolumn{4}{|c|}{ Computational Criteria }} & \multicolumn{9}{|c|}{ Case Studies } \\
\hline & & & & & & \multirow{2}{*}{\multicolumn{3}{|c|}{$\begin{array}{l}\text { Architectural } \\
\text { Scales }\end{array}$}} & \multicolumn{6}{|c|}{ Functional Utilities } \\
\hline & & & & & & & & & \multicolumn{6}{|c|}{ Housing } \\
\hline & & A & B & $\mathrm{C}$ & D & E & F & G & $\mathbf{H}$ & I & $\mathbf{J}$ & $\mathbf{K}$ & $\mathbf{L}$ & $\mathbf{M}$ \\
\hline \multicolumn{15}{|c|}{ Solar Obstruction Angle (SOA) } \\
\hline$[63]$ & - & $\bullet$ & & & $\bullet$ & $\bullet$ & $\bullet$ & & & - & & & - & - \\
\hline$[33]$ & The Obstrucao 1.0 & $\bullet$ & & $\bullet$ & $\bullet$ & & & $\bullet$ & - & & & & & \\
\hline$[64-66]$ & MascaraW & $\bullet$ & & $\bullet$ & $\bullet$ & $\bullet$ & & $\bullet$ & & & - & & & \\
\hline$[67,68]$ & $\begin{array}{c}\text { CityZoom (Block magic } \\
\text { 3D) }\end{array}$ & • & & $\bullet$ & $\bullet$ & $\bullet$ & & • & & & & $\bullet$ & & • \\
\hline$[69]$ & - & & & & & $\bullet$ & & - & & & & & $\bullet$ & \\
\hline$[70]$ & $\begin{array}{l}\text { Envi-met (thermal } \\
\text { analysis), PMV }\end{array}$ & & $\bullet$ & $\bullet$ & $\bullet$ & & $\bullet$ & • & $\bullet$ & & & & & \\
\hline$[71,72]$ & CAD-Microstation & & & $\bullet$ & $\bullet$ & & - & $\bullet$ & & & - & & & \\
\hline$[73,74]$ & BRADA & $\bullet$ & & • & - & $\bullet$ & & - & & & • & & & \\
\hline$[75,76]$ & $\begin{array}{l}\text { City SHADOWS, } \\
\text { Envi-met }\end{array}$ & $\bullet$ & & $\bullet$ & $\bullet$ & • & & $\bullet$ & & $\bullet$ & & & & \\
\hline \multicolumn{15}{|c|}{ Constructive Solar Geometry (CSG) } \\
\hline $\begin{array}{c}{[35,77,} \\
78]\end{array}$ & $\begin{array}{c}\text { Solar envelopes tools }+ \\
\text { BSK }\end{array}$ & & & $\bullet$ & $\bullet$ & $\bullet$ & & - & & & $\bullet$ & & & \\
\hline$[30,34]$ & AutoCAD 2000 & & & $\bullet$ & & $\bullet$ & & $\bullet$ & & & & $\bullet$ & & - \\
\hline$[36]$ & $\begin{array}{c}\text { CalcSolar } \\
\text { (Autolisp)-Autocad }\end{array}$ & - & & • & & & & - & & & & $\bullet$ & & \\
\hline$[39]$ & GIS, EnergyPlus 8.1 & & & - & $\bullet$ & - & & - & & - & & & & \\
\hline [37] & Form.Z & & & • & & & & - & & & & - & & \\
\hline [79] & SolCAD & - & & - & & & - & - & & & & $\bullet$ & & \\
\hline$[38,80]$ & $\begin{array}{l}\text { Rhino, Grasshopper, } \\
\text { EnergyPlus }\end{array}$ & & $\bullet$ & $\bullet$ & $\bullet$ & & & • & & & & & $\bullet$ & \\
\hline$[81]$ & $\begin{array}{l}\text { Rhino, Grasshopper, } \\
\text { Ladybug }\end{array}$ & & $\bullet$ & $\bullet$ & $\bullet$ & & & $\bullet$ & $\bullet$ & & & & $\bullet$ & \\
\hline$[82]$ & $\begin{array}{l}\text { Rhino, Grasshopper, } \\
\text { Ladybug }\end{array}$ & & $\bullet$ & $\bullet$ & $\bullet$ & & & • & $\bullet$ & & & $\bullet$ & • & \\
\hline [83] & $\begin{array}{l}\text { Rhino, Grasshopper, } \\
\text { Ladybug }\end{array}$ & & $\bullet$ & $\bullet$ & $\bullet$ & & & $\bullet$ & $\bullet$ & & & & $\bullet$ & \\
\hline$[84,85]$ & PIRAMIDA & $\bullet$ & & $\bullet$ & $\bullet$ & & & $\bullet$ & & - & & & & \\
\hline$[15,86]$ & Autodesk's 3dsmax ${ }^{\mathrm{TM}}$ & & & • & $\bullet$ & $\bullet$ & & - & & & & $\bullet$ & $\bullet$ & \\
\hline [87] & AutoCAD & & & - & $\bullet$ & & & - & & - & & & & \\
\hline$[88]$ & $\begin{array}{c}\text { Rhino, Grasshopper, } \\
\text { Ladybug }\end{array}$ & & $\bullet$ & $\bullet$ & $\bullet$ & & & $\bullet$ & $\bullet$ & & & & $\bullet$ & $\bullet$ \\
\hline
\end{tabular}

A: Self-developed; B: Dynamic parameter input; C: Parametric modeling environment; D: Integrated environmental simulation; E: Urban; F: Open space; G: Single building; H: Discontinued collective; I: Continued collective; J: Dense individual; K: Dispersed individual; L: Offices; M: Commercial.

The distributions of these qualities are subsequently plotted onto the bar graph, as illustrated in Figure 5. The purpose is to identify the performance of each computational method in relation to the number of corresponding references for each criterion. In so doing, a better overview regarding the computational workflow of solar envelopes is developed, especially with respect to the context of design practices available for architectural use. 


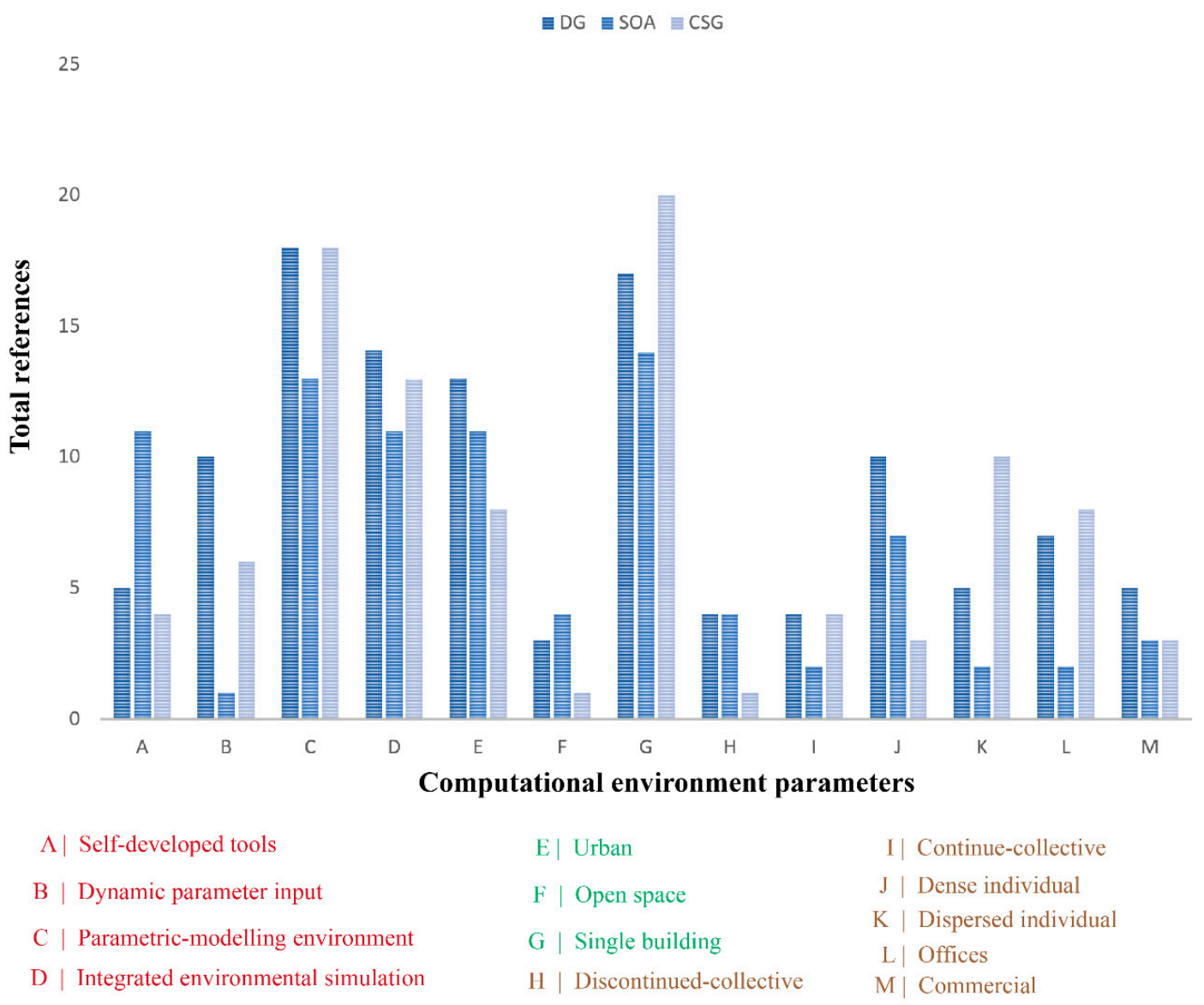

Figure 5. Distribution of computational environment parameters according to the corresponding computational methods.

\subsection{Digital Tools}

The simulation tools in each selected reference to construct solar envelopes are examined. According to Anderson [89], in Design Energy Simulation for Architects, the minimum requirement for design tools to run performance simulations consists of three components, specifically, a user interface, three-dimensional modelers, and an engine. Accordingly, several criteria are established to identify a general pattern of simulation platforms in relation to the computational methods of solar envelopes.

\section{- Self-developed tools}

Self-developed refers to the ease of access of the tools during the creation of solar envelopes. These tools are then defined according to three specific criteria. The first category of tools includes those preferred by authors who use popular CAD-related platforms to run the simulations of solar envelopes (e.g., $[30,34,45,46,51,60,71,72,87])$. The second category consists of a custom-built module that is generated from a particular function of existing digital tools such as T4SU in SketchUp [50], SolCAD [79] and Calcsolar [56] in Autocad, solar envelope tools in Revit [36], and the Solar Toolbox plugin in Grasshopper [90]. Third, a tailor-made supporting tools that perform specific tasks related to solar envelopes. Among these tools are The Obstrucao 1.0 [33], form Z [37], SustArc [40], Calcsolar-AutoLISP [56], MascaraW [66], CityZoom [68], CitySHADOWS [75,76], and PIRAMIDA $[84,85]$. Note that some references are found to be incomplete due to limited information during the review process, i.e., [ $44,47,59,61,63,69]$.

When these criteria are plotted with their corresponding methods and references in Figure 5 (see point A), it is evident that SOA exhibits the higher number of references, followed by DG and 
CSG given that SOA consists of the greatest number of local parameters. As previously elucidated in Figure 4, local parameters represent a series of parameters that only attach to a particular method due to their scarcity and complexity of use. Accordingly, SOA requires particular tools to formulate the appropriate parameters when constructing solar envelopes.

- Dynamic parameter input

This criterion emphasizes the flexibility between the fixed and adaptable-parameter algorithms. The fixed-parameter algorithm often includes both a static and a limited number of parameters due to the default system of design tools. Consequently, the end user of the tool can only follow the simulation procedure and input the dataset on the basis of the given parameters [36]. Some design tools, however, consist of adaptable or dynamic parameters that permit additional tasks, such as the reduction in the number of and generation of relevant parameters. These tasks provide a direct interaction between the users and the tools when developing a solar envelope simulation.

To create a legible representation, Figure 5 (see point B) specifically illustrates a bar graph of references that corresponds to the dynamic parameter inputs. The graph indicates that DG has the highest number of dynamic parameter input references, followed by CSG and SOA. This trend is relevant to all methods, however, as DG simultaneously also consists of the largest quantity of references. As the most frequently-used and flexible method (see Figure 3), DG provides great accessibility for using the existing digital tools during the construction of solar envelopes. Table 2 (see the digital tools) illustrates that DG predominantly uses a well-known tool with a wide input of parameters.

- Modeling environment

According to the geometric representation, the modeling environment of the selected references is predominantly generated based on NURBS (non-uniform rational B-spline) models that range from the organic free-form surface to the 3D solid model [31]. The NURBS models are further divided into parametric and direct modeling approach models. These approaches not only differ with respect to design rule and process but also in the complexity of geometrical parameters. Accordingly, the geometric configuration of solar envelopes is dependent on the applied algorithm of the modeling approach. For example, the surface representation of the 3D model can geometrically vary when generated from the TIN (triangulation irregular network) of the point cloud compared to one that is manually created based on the CAD platform [91].

According to Figure 5 (see point C), the total number of references for the DG and CSG methods are equally proportioned and outnumber the studies the reference for the SOA method. This trend represents the total selected references for all methods, except some references for unidentified tools. This is because all methods use design tools with parametric functions during the construction of solar envelopes. Nonetheless, further research is required to identify the geometrical behaviors generated by the interaction of parameters.

- Integrated environmental performances

Interoperability plays an important role during the design process, especially when dealing with various simulation tools and multiple dataset sources. While this can create, to some extent, a computational issue due to different algorithmic operations, a comprehensive analysis for optimal design solution can be achieved. With an integrated environmental simulation, the computational functions of certain design tools, such as solar thermal exposure [61], wind analysis [42], daylight availability, solar photovoltaic exposure, ventilation enhancement, and water surface catchment and flow [92], can be extended during the construction of solar envelopes.

In general, the trend in Figure 5 (see point D) illustrates high percentages regarding the use of environmental performances in all methods. This results means that most of the selected studies performed one or more environmental simulation during the construction of solar envelopes. According to the stage of use during the simulation process, these environmental performances can be categorized into three functions, namely, generator, evaluator, and generator, as well as evaluators 
that are operated in the same workflow. For example, first, the performance generator is used to support the main parameter to establish the final geometry of solar envelopes. Some example of performances can be observed in DG that includes direct sun access duration, temperature [43], annual space heating demands, daylight, thermal performances, solar renewables [53], wind analysis [59], visual assessment, street network [54,55], and solar irradiation [57,58], while in SOA urban heat islands [71,72] and daylight [73,74], and CSG consists of sun hours availability [88]. Second, the performance evaluator is employed to assess the final geometry of solar envelopes. In other words, this process measures the environmental impacts of new envelopes and compares those impacts to previous and existing conditions. Examples of these criteria are found in DG with performances that involve urban density, direct sun access duration [49], and solar irradiation [52], SOA with energy consumption [33], temperature, wind, albedo, thermal comfort [70], urban heat island, and daily direct solar radiation [75,76], CSG with aeshthetics, solar access, lighting, ventilation, public safety $[35,77,78]$, solar access hours, annual energy consumption, cost, CO2e [38,80], urban density [15,86], and sunlight and shading simulation [87]. Third, the performance generator and evaluator consist of a combination of two types of performances that are operated simultaneously in one workflow. For example, some studies on DG use performances such as urban density, energy consumption [32,41,42], temperature, wind, climate, and energy [61], while references in the SOA category consider insolation hours, urban density [63], comfort issues and wind flows [67,68], and those in CSG involve more performances related to air temperatures, global radiation, passive solar gains, heating loads, insolation values [39], sun access duration [81], building density [82], and sphere view factors [83].

\subsection{Case Studies}

To identify the contextual settings of computational solar envelopes in design practices, this study separates and plots the selected references in two functions, namely, architectural scales and functional utilities. According to Figure 5 (see points E-G), case studies of solar envelopes are predominantly implemented in single buildings since the building-oriented context requires fewer geographic parameters than do urban scales. For example, the CSG method has the greatest number of references with a single building context (see Figure 5 point G), but it receives the lowest rate for implementation in urban contexts (see Figure 5 point E) because the modeling construction of CSG is more appropriate for building contexts than for urban-scale contexts due to the high cost of computational issues. The context of open space, however, has received less attention. In fact, open space only seems to play an essential role during the construction of solar envelopes, particularly in highly dense areas such as metropolitan cities.

The functional utilities of the projects are divided into three types, namely, housing, offices, and commercial. The housing category includes those typologies proposed by Maizea et al. [93] and thus, consists of the discontinued collective, continued collective, dense individual, and dispersed individual. In general, the trend of this housing category suggests that the 'individual' groups are referenced more frequently than the 'collective' groups due to the complexity of the projects and scale of the plots. Accordingly, the DG and CSG method are referenced more often in the dense individual and dispersed individual groups, respectively.

With respect to the comparison of housing group and other functions, such as offices and commercial properties, Figure 5 illustrates that of all the functional utilities, housing is the one most referenced, even though most people who live in big cities or dense areas spend far more time in offices during the day. Accordingly, solar envelopes are crucial to providing sunlight penetration to the working space to reduce energy consumption during working hours. Consistent with this fact, solar envelopes also play an important role in determining specific conditions of commercial areas. For example, as direct sunlight can affect food and product durability issues, especially when located in ground floor level storefronts, shading becomes a critical factor. However, as some references do not include a specific function for the implementation of a case study, it is challenging to understand 
the relationship between the contextual settings of these references and performance criteria of the solar envelopes.

\section{Knowledge Gaps and New Directions}

Based on the understanding of the computational methods of solar envelopes presented in the previous sections, this study identifies several gaps that may drive further research for new approaches to the generation of solar envelopes (see Table 3). These gaps are formulated into three aspects, namely, 3D contextual model, climatic properties, and geometric configuration. The proposed directions are also discussed in relation to each gap.

Table 3. Knowledge gaps and new directions for solar envelopes.

\begin{tabular}{|c|c|c|c|}
\hline No. & Qualities & Knowledge Gaps & Future Directions \\
\hline \multirow{2}{*}{1.} & \multirow{2}{*}{$\begin{array}{l}\text { 3D contextual } \\
\text { model }\end{array}$} & $\begin{array}{l}\text { Limited discussion on covering } \\
\text { contextual geometries }\end{array}$ & \multirow{2}{*}{$\begin{array}{l}\text { DEM (digital elevation modeling) } \\
\text { Point cloud data }\end{array}$} \\
\hline & & $\begin{array}{l}\text { Limited understanding of site } \\
\text { characteristics information }\end{array}$ & \\
\hline \multirow{3}{*}{2.} & \multirow{3}{*}{$\begin{array}{l}\text { Climatic } \\
\text { properties }\end{array}$} & $\begin{array}{l}\text { Predominantly based on } \\
\text { four-season countries }\end{array}$ & Tropical countries \\
\hline & & $\begin{array}{c}\text { The objective is to collect } \\
\text { direct sunlight }\end{array}$ & $\begin{array}{l}\text { The objective is to avoid direct sun } \\
\text { access }\end{array}$ \\
\hline & & $\begin{array}{l}\text { Predefined period only relies on } \\
\text { cut-off times }\end{array}$ & Consider sun visibility on each period \\
\hline \multirow{3}{*}{3.} & \multirow{3}{*}{$\begin{array}{l}\text { Geometric } \\
\text { configuration }\end{array}$} & $\begin{array}{l}\text { Limited results on final geometry of } \\
\text { solar envelopes }\end{array}$ & Multi objective optimization \\
\hline & & Limited performance criteria & $\begin{array}{l}\text { Integrate multi performance criteria } \\
\text { (e.g., material) }\end{array}$ \\
\hline & & $\begin{array}{l}\text { Focuses only on 3D mass of } \\
\text { solar envelopes }\end{array}$ & $\begin{array}{l}\text { Explore performance configuration of } \\
\text { the layout of the building's interior. }\end{array}$ \\
\hline
\end{tabular}

- 3D contextual model

As previously described, most of the current methods employ solid modeling as a platform of the 3D contextual model. Most important when considering this approach is the challenge to comprehensively understand the characteristics of the existing contexts, especially when dealing with complex sites. The current approach to 3D site modeling often not only fails to preserve geometric aspects of existing context but also fails to sufficiently address the surrounding site properties, such as vegetation or other temporal site elements that may be relevant for further analyses of solar envelopes. Moreover, the surface characteristics of the existing environment, such as the material of surrounding facades, have also received less attention to date. That said, it is argued that the calculations of solar energy within solar envelopes should take into account the surface characteristics of the surrounding environment.

An alternative to the aforementioned issues is digital elevation modeling (DEM). In comparison with other solar envelope methods that are created primarily by CAD drawings, the DEM platform employs image processing techniques to obtain and quantify a solar exposure map by means of shadow volumes $([94,95])$. This approach includes iso-solar rights and iso-solar collection surfaces to implement energy-oriented shapes in urban environments. As the current DEM method predominantly focuses on the urban scale, it remains challenging to identify and calculate specific geometric parameters, such as building scales. Another consideration is the 3D laser scanning technologies that offer opportunities to capture the physical properties of the environment. As a product of laser scanner, potential applications 
of point cloud data may counterbalance relevant information within the surrounding context using geometric and radiometric properties.

- Climatic properties

With respect to the climatic parameters found within the collected literature, the existing studies are based primarily on four-season countries. This means that their objectives focus on minimizing sun access duration during summer while maximizing it during winter so that the sunlight can penetrate the main activity room. In fact, these objectives differ significantly from those of tropical countries, especially for those countries located on the equator. Since tropical countries consist of annual wet and dry seasons, these climatic factors affect the objectives and mechanisms of solar envelopes, and accordingly, solar envelopes should be able to minimize the sunlight coming into the house due to high temperatures. For example, building constructions in Indonesia prefer shaded conditions to lower the hot temperatures inside the building. Accordingly, the concepts and existing parameters of solar envelopes require further adjustments for tropical contexts.

- Geometric configuration

During the schematic design phase, it is often important to analyze the solar access of new buildings when selecting the optimal layouts for massing that fulfils the volumetric shape of solar envelopes. Accordingly, the solar collection envelope (SCE) [32] and solar collection multi-isosurface [49] have been developed. However, solar collection surfaces can only be used for single buildings with rectangular or convex footprint layouts. Thus, further research is needed to identify optimal massing and layouts for articulated buildings and clusters in urban environments. Hence, the concept of multi objective optimization is useful for exploring geometric design configurations of solar envelopes to identify the optimal solution.

\section{Conclusions}

This study presents a conceptual review of solar envelopes by investigating the qualities of design methods and computational performance aspects in relation to parameters, digital simulation tools, and implementation of the case studies. In particular, 58 selected references of solar envelopes are extensively examined as the basis idea to perform comparative analysis between each categorized method and predefined criteria. This study ultimately allows architects not only to identify different characteristics and levels of complexity for each design method but more importantly also to address the concept of solar envelopes in design practices such as the projects of P15 Ravel Plot and Grotius Towers II by the Dutch architectural and urban design firm MVRDV. As a research framework, the present study may also benefit further for urban planner and related municipality to update the current parameters of local regulation especially related to solar energy building performances and environmental design assessments between proposed building and existing environment. Specific remarks on each section in this review are presented as follows:

- By categorizing the contextual setting of solar envelopes into the inclusion and exclusion of surrounding properties (e.g., vegetation, adjacent buildings, open spaces, and other relevant elements) enables architects to identify the types of methods that predominantly focus on new or existing contexts. Given that urban densities may have scarcity of wide areas, DG plays an essential part to deal with the future scenarios as it considers more site properties than other methods.

- Categorization of design parameters into geographic and climatic properties allows us to identify specific parameters that affect volumetric size of solar envelopes for each design method.

- The comparative analysis among methods and parameters indicates that DG is the most frequently-used method of the three. This is because DG has the greatest number of registered references and thus, it contains more basic parameters (latitude, orientation, cut-off times, and solar altitudes) as compared to other methods. In addition, DG has the greatest flexibility to 
switch parameters during the establishment of solar envelopes because of its wide range of complementary parameters.

- This study categorizes SOA and CSG method as a group with the low category parameters and thus, it refers to local parameters because their parameters can only apply to particular cases when establishing solar envelopes.

- This study investigates the geometric performance of each solar envelope method with respect to the predefined criteria of the digital tools. For example, SOA is identified as the method with the greatest use of self-developed tools since it has the greatest number of local parameters. In contrast, DG is the most flexible for constructing solar envelopes due to its great accessibility, its ability to use the existing digital tools, and its wide range of dynamic parameter inputs.

- This study identifies that CSG is predominantly implemented in a single building rather than on an urban scale due to the high cost of computational modeling and the mesh generation procedures. Moreover, this study reveals that housing remains a predominant case study of solar envelopes, even though offices and commercial sectors consume a greater portion of urban functions, especially in dense areas.

Furthermore, although the conceptual framework of computational solar envelopes is extensively addressed in this review, there is still a need for an objective evaluation approach to provide a quantitative analysis of different methods. By using a similar set of predefined parameters, digital tools, and case study, volumetric shape and performance criteria of geometric solar envelopes on different methods can be further measured more precisely.

Author Contributions: Conceptualization, F.D.L. and M.F.A.; methodology, M.T.; writing-original draft preparation, M.F.A.; writing-review and editing, M.T. and F.D.L.; visualization, M.F.A.; supervision, S.S.; All authors have read and agreed to the published version of the manuscript.

Funding: This research was funded by Indonesia Endowment Fund for Education (LPDP) as a part of PhD Research of the first author under the chair of Design Informatics, Faculty of Architecture and the Built Environment of TU Delft. In addition, the European Regional Development Fund grant (the Estonian Centre of Excellence in Zero Energy Resource Efficient Smart Buildings and Districts) ZEBE n. 2014-2020.4.01.15-0016 and the European Commission H2020 grant Finest Twins n. 856602 are used to support the work of the second author.

Acknowledgments: The authors would like to thank TU Delft Library for supporting logistics of this publication. Conflicts of Interest: The authors declare no conflict of interest. 


\section{Appendix A}

Table A1. Parameters selection for reference databases.

\begin{tabular}{|c|c|c|c|c|}
\hline \multirow{5}{*}{ 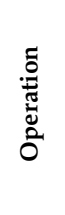 } & \multirow{5}{*}{ 巡 } & \multicolumn{3}{|c|}{ Topics } \\
\hline & & Conceptual Themes & Design Workflow & Contextual Settings \\
\hline & & Solar Architecture & Computational Design & Urban Planning \\
\hline & & Solar Envelopes & Solar Design & Urban Design \\
\hline & & Solar Access & Solar Simulation & Architectural Design \\
\hline \multirow[t]{6}{*}{ OR } & WoS & $\begin{array}{c}\text { TOPIC: (“solar architecture" OR } \\
\text { "solar envelopes” OR “solar } \\
\text { access") } \\
\text { Refined by: WEB OF SCIENCE } \\
\text { CATEGORIES: } \\
\text { (CONSTRUCTION BUILDING } \\
\text { TECHNOLOGY OR } \\
\text { ARCHITECTURE OR GREEN } \\
\text { SUSTAINABLE SCIENCE } \\
\text { TECHNOLOGY OR } \\
\text { ENGINEERING CIVIL OR } \\
\text { URBAN STUDIES OR } \\
\text { COMPUTER SCIENCE } \\
\text { INTERDISCIPLINARY } \\
\text { APPLICATIONS OR } \\
\text { ENGINEERING } \\
\text { MULTIDISCIPLINARY) AND } \\
\text { DOCUMENT TYPES: (ARTICLE } \\
\text { OR BOOK CHAPTER OR } \\
\text { PROCEEDINGS PAPER) AND } \\
\text { RESEARCH AREAS: } \\
\text { (CONSTRUCTION BUILDING } \\
\text { TECHNOLOGY OR } \\
\text { ENGINEERING OR } \\
\text { ARCHITECTURE OR URBAN } \\
\text { STUDIES) } \\
\text { TimesPan: 1960-2019. Indexes: } \\
\text { SCI-EXPANDED, SSCI, A\&HCI, } \\
\text { CPCI-S, CPCI-SSH, BKCI-S, } \\
\text { BKCI-SSH, ESCI, } \\
\text { CCR-EXPANDED, IC }\end{array}$ & $\begin{array}{c}\text { TOPIC: (“computational design” } \\
\text { OR “solar design” OR “solar } \\
\text { simulation”) } \\
\text { Refined by: WEB OF SCIENCE } \\
\text { CATEGORIES: (COMPUTER } \\
\text { SCIENCE INTERDISCIPLINARY } \\
\text { APPLICATIONS OR } \\
\text { ARCHITECTURE OR } \\
\text { ENGINEERING } \\
\text { MULTIDISCIPLINARY OR } \\
\text { CONSTRUCTION BUILDING } \\
\text { TECHNOLOGY OR } \\
\text { ENGINEERING CIVIL OR } \\
\text { GREEN SUSTAINABLE SCIENCE } \\
\text { TECHNOLOGY) AND } \\
\text { DOCUMENT TYPES: (ARTICLE } \\
\text { OR BOOK CHAPTER OR } \\
\text { PROCEEDINGS PAPER) AND } \\
\text { RESEARCH AREAS: } \\
\text { (COMPUTER SCIENCE OR } \\
\text { ENGINEERING OR } \\
\text { ARCHITECTURE OR } \\
\text { CONSTRUCTION BUILDING } \\
\text { TECHNOLOGY OR URBAN } \\
\text { STUDIES) } \\
\text { Timespan: 1960-2019. Indexes: } \\
\text { SCI-EXPANDED, SSCI, A\&HCI, } \\
\text { CPCI-S, CPCI-SSH, BKCI-S, } \\
\text { BKCI-SSH, ESCI, } \\
\text { CCR-EXPANDED, IC }\end{array}$ & $\begin{array}{c}\text { TOPIC: (“urban planning” OR } \\
\text { “urban design” OR “architectural } \\
\text { design”) } \\
\text { Refined by: WEB OF SCIENCE } \\
\text { CATEGORIES: (URBAN STUDIES } \\
\text { OR ARCHITECTURE OR } \\
\text { REGIONAL URBAN PLANNING } \\
\text { OR ENGINEERING CIVIL OR } \\
\text { CONSTRUCTION BUILDING } \\
\text { TECHNOLOGY OR GREEN } \\
\text { SUSTAINABLE SCIENCE } \\
\text { TECHNOLOGY) AND } \\
\text { DOCUMENT TYPES: (ARTICLE } \\
\text { OR PROCEEDINGS PAPER OR } \\
\text { BOOK OR BOOK CHAPTER) } \\
\text { AND RESEARCH AREAS: } \\
\text { (URBAN STUDIES OR } \\
\text { ARCHITECTURE OR } \\
\text { ENGINEERING OR } \\
\text { CONSTRUCTION BUILDING } \\
\text { TECHNOLOGY) } \\
\text { Timespan: 1960-2019. Indexes: } \\
\text { SCI-EXPANDED, SSCI, A\&HCI, } \\
\text { CPCI-S, CPCI-SSH, BKCI-S, } \\
\text { BKCI-SSH, ESCI, } \\
\text { CCR-EXPANDED, IC }\end{array}$ \\
\hline & Total & 139 & 846 & 10.196 \\
\hline & Scopus & 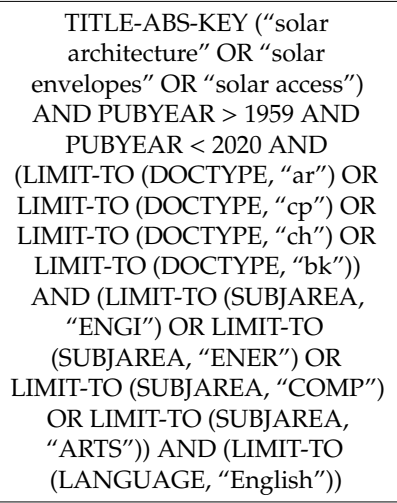 & $\begin{array}{l}\text { TITLE-ABS-KEY (“computational } \\
\text { design" OR “solar design" OR } \\
\text { "solar simulation") AND } \\
\text { PUBYEAR > } 1959 \text { AND } \\
\text { PUBYEAR < 2020 AND } \\
\text { (LIMIT-TO (DOCTYPE, “ar") OR } \\
\text { LIMIT-TO (DOCTYPE, "cp") OR } \\
\text { LIMIT-TO (DOCTYPE, "ch") OR } \\
\text { LIMIT-TO (DOCTYPE, “bk")) } \\
\text { AND (LIMIT-TO (SUBJAREA, } \\
\text { "ENGI") OR LIMIT-TO } \\
\text { (SUBJAREA, “COMP”) OR } \\
\text { LIMIT-TO (SUBJAREA, “ENER")) } \\
\text { AND (LIMIT-TO (LANGUAGE, } \\
\text { "English")) }\end{array}$ & 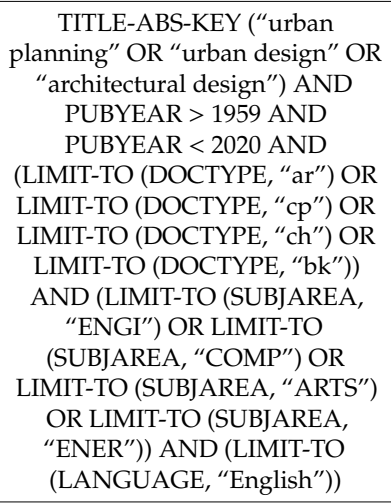 \\
\hline & Total & 388 & 2.548 & 61.900 \\
\hline & GS & $\begin{array}{l}\text { Sort by date: "solar architecture" } \\
\text { OR "solar envelopes" OR "solar } \\
\text { access" }\end{array}$ & $\begin{array}{l}\text { Sort by date: "computational } \\
\text { design" OR "solar design" OR } \\
\text { "solar simulation" }\end{array}$ & $\begin{array}{l}\text { Sort by date: "urban planning" } \\
\text { OR "urban design" OR } \\
\text { "architectural design" }\end{array}$ \\
\hline & Total & 43 & 674 & 8.530 \\
\hline
\end{tabular}


Table A1. Cont.

\begin{tabular}{|c|c|c|c|c|}
\hline \multirow{5}{*}{ 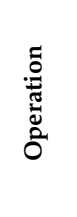 } & \multirow{5}{*}{ 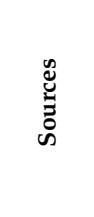 } & \multicolumn{3}{|c|}{ Topics } \\
\hline & & Conceptual Themes & Design Workflow & Contextual Settings \\
\hline & & Solar Architecture & Computational Design & Urban Planning \\
\hline & & Solar Envelopes & Solar Design & Urban Design \\
\hline & & Solar Access & Solar Simulation & Architectural Design \\
\hline \multirow[t]{6}{*}{ AND } & WoS & \multicolumn{3}{|c|}{$\begin{array}{l}\text { TOPIC: ("solar architecture" OR "solar envelopes" OR "solar access" AND "computational design" OR "solar } \\
\text { design" OR “solar simulation" AND “urban planning" OR "urban design" OR “architectural design") } \\
\text { Refined by: WEB OF SCIENCE CATEGORIES: (ARCHITECTURE OR URBAN STUDIES OR } \\
\text { CONSTRUCTION BUILDING TECHNOLOGY OR ENGINEERING CIVIL OR REGIONAL URBAN } \\
\text { PLANNING OR GREEN SUSTAINABLE SCIENCE TECHNOLOGY) AND DOCUMENT TYPES: (ARTICLE } \\
\text { OR PROCEEDINGS PAPER OR BOOK CHAPTER OR BOOK) AND RESEARCH AREAS: (ARCHITECTURE } \\
\text { OR URBAN STUDIES OR ENGINEERING OR CONSTRUCTION BUILDING TECHNOLOGY) } \\
\text { Timespan: 1960-2019. Indexes: SCI-EXPANDED, SSCI, A\&HCI, CPCI-S, CPCI-SSH, BKCI-S, BKCI-SSH, ESCI, } \\
\text { CCR-EXPANDED, IC }\end{array}$} \\
\hline & Total & \multicolumn{3}{|c|}{5.592} \\
\hline & Scopus & \multicolumn{3}{|c|}{$\begin{array}{c}\text { TITLE-ABS-KEY ("solar architecture" OR “solar envelopes" OR "solar access" AND "computational design" } \\
\text { OR "solar design" OR "solar simulation" AND "urban planning" OR “urban design" OR "architectural } \\
\text { design") AND PUBYEAR > } 1959 \text { AND PUBYEAR }<2020\end{array}$} \\
\hline & Total & \multicolumn{3}{|c|}{13} \\
\hline & GS & \multicolumn{3}{|c|}{$\begin{array}{l}\text { Sort by date: "solar architecture" OR "solar envelopes" OR "solar access" AND "computational design" OR } \\
\text { "solar design" OR "solar simulation" AND "urban planning" OR "urban design" OR "architectural design" }\end{array}$} \\
\hline & Total & \multicolumn{3}{|c|}{1050} \\
\hline
\end{tabular}

\section{References}

1. Ritchie, H.; Roser, M. Urbanization. 2020. Available online: https://ourworldindata.org/urbanization (accessed on 30 January 2020).

2. United Nations. World Urbanization Prospects: The 2018 Revision (ST/ESA/SER.A/420); Department of Economic and Social Affairs, Population Division: New York, NY, USA, 2019.

3. IEO. International Energy Outlook 2019 with Projections to 2050; U.S. Energy Information Administration Office of Energy Analysis, U.S. Department of Energy: Washington, DC, USA, 2019.

4. Global Alliance for Bbuildings and Construction, International Energy Agency and the United Nations Environment Programme. 2019 Global Status Report for Building and Construction: Towards a Zero-Emissions, Efficient and Resilient Buildings and Construction Sector; United Nations Environment Programme: Madrid, Spain, 2019.

5. Chan, A.P.; Darko, A.; Ameyaw, E.E. Strategies for promoting green building technologies adoption in the construction industry-An international study. Sustainability 2017, 9, 969. [CrossRef]

6. Martin, L.; Perry, F. Sustainable construction technology adoption. In Sustainable Construction Technologies; Life-Cycle Assessment:Butterworth-Heinemann: Kidlington, UK; Oxford, UK, 2019; pp. 299-316.

7. Anand, P.; Sekhar, C.; Cheong, D.; Santamouris, M.; Kondepudi, S. Occupancy-based zone-level VAV system control implications on thermal comfort, ventilation, indoor air quality and building energy efficiency. Energy Build. 2019, 2014, 109473. [CrossRef]

8. Shin, M.; Baltazar, J.-C.; Haberl, J.S.; Frazier, E.; Lynn, B. Evaluation of the energy performance of a net zero energy building in a hot and humid climate. Energy Build. 2019, 204, 10953. [CrossRef]

9. Ahmad, M.W.; Mourshed, M.; Yuce, B.; Rezgui, Y. Computational intelligence techniques for HVAC systems: A review. Build. Simul. 2016, 9, 359-398. [CrossRef]

10. Reijula, J.; Holopainen, R.; Kähkönen, E.; Reijula, K.; Tommelein, I.D. Intelligent HVAC systems in hospitals. Intell. Build. Int. 2013, 5, 101-119. [CrossRef]

11. Winy, M. What's Next? How Do We Make Vertical Urban Design? Council on Tall Buildings and Urban Habitat (CTBUH): Shenzen, China, 2016.

12. MVRDV. Grotius Towers. MVRDV. 2019. Available online: https://www.mvrdv.nl/projects/392/grotius-towers (accessed on 27 May 2020).

13. Topaloglu, B. Solar Envelope and Form Generation in Architecture. Master Thesis, Graduate School of Natural and Applied Sciences of the Middle East Technical University, Ankara, Turkey, 2003.

14. Knowles, R.L. Sun, Rhythm and Form; The MIT Press: Cambridge, MA, USA, 1981. 
15. White, M. Preserving Open Space Amenity Using Subtractive Volumetric Modelling; Aachener Geographische Arbeiten: Aachen, Germany, 2014.

16. Martín-Martín, A.; Orduna-Malea, E.; Thelwall, M.; López-Cózara, E.D. Google Scholar, Web of Science, and Scopus: A systematic comparison of citations in 252 subject categories. J. Informetr. 2018, 12, 1160-1177. [CrossRef]

17. Yang, K.; Meho, L. Citation Analysis: A Comparison of Google Scholar, Scopus, and Web of Science. Proc. Am. Soc. Inf. Sci. Technol. 2007, 43, 1-15. [CrossRef]

18. Knowles, R.L. Energy and Form: An Ecological Approach to Urban Growth; The MIT Press: Cambridge, MA, USA, 1974.

19. Giacomo, L. The Architecture of A. Palladio in Four Books; John Watts: London, UK, 1715.

20. Galton, D.S. Healthy Hospitals: Observations on some Points Connected with Hospital Construction, 1st ed.; Clarendon Press: London, UK; Oxford, UK, 1893.

21. Atkinson, W. The Orientation of Buildings: Or, Planning for Sunlight, 1st ed.; Wiley \& Sons: New York, NY, USA, 1912.

22. Leidi, M.; Schlüter, A. Exploring urban space-Volumetric site analysis for conceptual design in the urban context. Int. J. Archit. Comput. 2013, 11, 157-182. [CrossRef]

23. Da Veiga, J.; la Roche, P. A Computer Solar Analysis Tool for the Design and Manufacturing of Complex Architectural Envelopes: EvSurf. In Proceedings of the 6th Iberoamerican Congress of Digital Graphics [SIGraDi 2002], Caracas, Venezuela, 27-29 November 2002.

24. Littlefair, P. Passive solar urban design: Ensuring the penetration of solar energy into the city. Renew. Sustain. Energy Rev. 1998, 2, 303-326. [CrossRef]

25. Obaidat, B.S. A Simulation Model for Defining Three Different Solar Accesses in Site Planning. Simulation 1995, 65, 357-371. [CrossRef]

26. Jain, A.; Kensek, K.; Noble, D. Interactive Web-based teaching tool for simplified 3D analysis of solar rhythms. Autom. Constr. 1998, 8, 181-194. [CrossRef]

27. Ralegaonkar, R.V.; Gupta, R. Review of intelligent building construction: A passive solar architecture approach. Renew. Sustain. Energy Rev. 2010, 14, 2238-2242. [CrossRef]

28. Freita, S.; Catita, C.M.; Redweik, P.; Brito, M. Modelling solar potential in the urban environment: State-of-the-art-review. Renew. Sustain. Energy Rev. 2015, 41, 915-931. [CrossRef]

29. Lobaccaro, G.; Frontini, F.; Masera, G.; Poli, T. SolarPW: A new solar design tool to exploit solar potential in existing urban areas. Energy Procedia 2012, 30, 1173-1183. [CrossRef]

30. Stasinopoulos, T.N. A survey of solar envelope properties using solid modelling. J. Green Build. 2018, 13, 3-30. [CrossRef]

31. Staneva, N.N. Approaches for generating 3D solid models in AutoCAD and solid works. J. Eng. 2008, VI, 28-31.

32. Capeluto, G.; Shaviv, E. Modeling the design of urban grids and fabric with solar rights considerations. In Proceedings of the ISES, Taejon, Korea, 24-29 August 1997.

33. Brandao, R.S.; Alucci, M.P. Solar access in tropical cities: Towards a multicriteria solar envelope. In Proceedings of the 22nd Conference on Passive and Low Energy Architecture, Beirut, Lebanon, 13-16 November 2005.

34. Stasinopoulos, T.N. Solar Envelope-A Construction Method Using AutoCAD 2000. 9 July 2001. Available online: http://www.oikotekton.eu/solenvelope (accessed on 25 October 2016).

35. Raboudi, K.; Saci, A.B. A morphological generator of urban rules of solar control. In Proceedings of the 29th conference on PLEA 2013-Sustainable architecture for a renewable future, Munich, Germany, 10-12 September 2013.

36. Kensek, K.; Henkhaus, A. Solar Access Zoning + Building Information Modeling; Solar: Baltimore, MD, USA, 2013.

37. Cotton, J.F. Solid modeling as a tool for constructing solar envelopes. Autom. Constr. 1996, 5, 185-192. [CrossRef]

38. Niemasz, J.; Sargent, J.; Reinhart, C.F. Solar Zoning and Energy in Detached Dwellings; SimAUD: Boston, MA, USA, 2011.

39. Vartholomaios, A. The residential solar block envelope: A method for enabling the development of compact urban blocks with high passive solar potential. Energy Build. 2015, 99, 303-312. [CrossRef] 
40. Capeluto, I.G.; Shaviv, E. Modelling the design of urban fabric with solar rights considerations. In Proceedings of the International Conference of IBPSA, Kyoto, Japan, 13-15 September 1999.

41. Capeluto, I.; Yezioro, A.; Bleiberg, T.; Shaviv, E. From computer models to simple design tools: Solar rights in the design of urban streets. In Proceedings of the Ninth international IBPSA conference, Montreal, QC, Canada, 15-18 August 2005.

42. Capeluto, I.G.; Yezioro, A.; Shaviv, E. Climactic aspects in urban design-A case study. Build. Environ. 2003, 38, 827-835. [CrossRef]

43. Capeluto, G.I.; Plotnikov, B. A method for the generation of climate-based, context-dependent parametric solar envelopes. Archit. Sci. Rev. 2017, 60, 395-407. [CrossRef]

44. Machacova, K.; Keppl, J.; Krajcovics, L. The Solar Envelope Method in Education at the Faculty of Architecture STU Bratislava; Central Europe towards Sustainable Building: Prague, Czech Republic, 2013.

45. Martin, C.L.; Keeffe, G. The Biomimetic solar city: Solar derived urban form using a forest-growth inspired methodology. In Proceedings of the 24th Conference on Passive and Low Energy Architecture, Singapore, 22-24 November 2007.

46. Martin, C.L.; Pilling, M.; Stott, C.; Walsh, V. The nectar project: Solar development of post-industrial urban communities. In Proceedings of the 27th Conference on Passive and Low Energy Architecture, Louvain-la-Neuve, Belgium, 13-15 July 2011.

47. Dekay, M. The implications of community gardening for land use and density. J. Archit. Plan. Res. 1997, 14, 126-149.

48. De Luca, F. Solar Envelope Optimization Method for Complex Urban Environments. In Proceedings of the CAADence in Architecture. Back to Command, Budapest, Hungary, 16-17 June 2016.

49. De Luca, F.; Voll, H. Computational Method for Variable Objectives and Context-Aware Solar Envelopes Generation. In Proceedings of the 8th Annual Symposium on Simulation for Architecture and Urban Design, SimAUD, Toronto, ON, Canada, 22-24 May 2017.

50. Leduc, T.; Hartwell, K. Limiting the Buildings' Envelopes in Order to Prevent the Surrounding Mask Effect: Towards an Efficient Implementation in the Context of SketchUp; PLEA, Design to Thrive: Edinburgh, Scotland, 2017.

51. Canan, F.; Tosunlar, M.B. The implementation of sustainable approach in the architectural design studio developing architectural designs using solar envelope methods. Iconarp Int. J. Archit. Plan. 2016, 4, 14-33. [CrossRef]

52. Franco, R.; Beckers, B. A study of solar access in Bogotá: The Las Nieves neighborhood. In Proceedings of the First International Conference on Urban Physics, Quito-Galápagos, Ecuador, 25 September-2 October 2016.

53. Bruce, G. High Density, Low Energy: Achieving Useful Solar Access for Dublin's Multi-Storey Apartment Developments; PLEA: Dublin, Ireland, 2008.

54. Saleh, M.M.; Al-Hagla, K. Parametric Urban Comfort Envelope: An Approach towards a Responsive Sustainable Urban Morphology. In Proceedings of the ICSAUD 2012: International Conference on Sustainable Architecture and Urban Design, Venice, Italy, 14-16 November 2012.

55. Saleh, M.M.; Al-hagla, K.S. Parametric urban comfort envelope: An approach toward a responsive sustainable urban morphology. Int. J. Civ. Environ. Struct. Constr. Archit. Eng. 2012, 6, 930-937.

56. Noble, D.; Kensek, K. Computer generated solar envelopes in architecture. J. Archit. 1998, 3, 117-127. [CrossRef]

57. Camporeale, P. Genetic algorithms applied to urban growth optimizing solar radiation. In Proceedings of the PLEA 2013 29th Conference Sustainable Architecture for a Renewable Future, Munich, Germany, 10-12 September 2013.

58. Camporeale, P. Genetic algorthims applied to urban growth optimization. In Proceedings of the eCAADe Computation and Performance 2013, Delft, The Netherlands, 18-20 September 2013.

59. Sorayaei, T.; Sorayaei, Z. An integrated approach to climate conscious urban design using solar envelope concept. Palma J. 2017, 16, 322-330.

60. Jaff, A.A.M. Solar envelope method and consideration of the effectiveness of construction density and settlement in Konya. J. Sol. Energy Res. 2017, 2, 27-31.

61. Mert, Y.; Saygin, N. Energetic and Exergetic Design Evaluations of a Building Block Based on a Hybrid Solar Envelope Method. In Exergy for a Better Environment and Improved Sustainability; Springer International Publishing: Cham, Grermany, 2018; pp. 515-531. 
62. Nazer, H.; Rodrigues, L. Solar access in high density urban developments: A representative case in Matlock. In Proceedings of the PLEA 2015, Bologna, Italy, 9-11 September 2015.

63. Capeluto, I.G.; Yezioro, A.; Bleiberg, T.; Shaviv, E. Solar rights in the design of urban spaces. In Proceedings of the 23rd Conference on Passive and Low Energy Architecture, Geneva, Switzerland, 6-8 September 2006.

64. Pereira, F.O.R.; Silva, C.A.N. A proposal for the implementation of the solar envelope in urban planning as a concept for regulating the occupation of urban area. In Proceedings of the PLEA 98-The 15th International Conference on Passive and Low Energy Architecture, Lisbon, Portugal, June 1998.

65. Pereira, F.O.R.; Silva, C.A.N. Sunlighting in the urban design: A computer-based method for solar and sky vault obstruction control. In Proceedings of the PLEA 96-The 13th International Conference on Passive and Low Energy Architecture, Louvain-la-Neuve, Belgium, July 1996.

66. Pereira, F.O.R.; Silva, C.A.N.; Turkienikz, B. A methodology for sunlight urban planning: A computer-based solar and sky vault obstruction analysis. Sol. Energy 2001, 70, 217-226. [CrossRef]

67. Turkienicz, B.; Goncalves, B.B.; Grazziotin, P. CityZoom:A Visualization Tool for the assessment of planning regulations. Int. J. Archit. Comput. 2008, 6, 79-95. [CrossRef]

68. Grazziotin, P.C.; Pereira, F.O.R.; Freitas, C.M.D.S.; Turkienicz, B. Integration of Sunlight Access Control to Building Potential Simulator; The Ibero-American Symposium on Computer Graphics: Guimaraes, Portugal, 2002.

69. Amaral, M.D.G.V.D. The application of solar architecture in the planning of the campus. In Proceedings of the 2005 World Sustainable Building Conference, Tokyo, Japan, 27-29 September 2005.

70. Paramita, B.; Koerniawan, M. Solar envelope assessment in tropical region building case study: Vertical settlement in Bandung, Indonesia. In Proceedings of the 3rd International Conference on Sustainable Future for Human Security SUSTAIN 2012, Kyoto, Japan, 3-5 November 2012.

71. Emmanuel, R. A hypothetical 'shadow umbrella' for thermal comfort enhancement in the equatorial urban outdoors. Archit. Sci. Rev. 1993, 36, 173-184. [CrossRef]

72. Emmanuel, R.; Rosenlund, H.; Johansson, E. Urban shading-A design option for the tropics? A study in Colombo, Sri Lanka. Int. J. Climatol. 2007, 27, 1995-2004. [CrossRef]

73. Dekay, M. Daylighting and urban form: An urban fabric of light. J. Archit. Plan. Res. 2010, 27, 35-56.

74. Dekay, M. Climatic urban design: Configuring the urban fabric to support daylighting, passive cooling, and solar heating. Sustain. City Vii 2012, 155, 619-630.

75. Okeil, A. A holistic approach to energy efficient building forms. Energy Build. 2010, 42, 1437-1444. [CrossRef]

76. Okeil, A. In Search for Energy Efficient Urban Forms: The Residential Solar Block. In Proceedings of the Building for the Future: The 16th CIB World Building Congress 2004, Toronto, ON, Canada, 2-7 May 2004.

77. Raboudi, K.; Saci, A.B. Conditions of satisfaction of the solar control box constraints. J. Civ. Eng. Archit. 2018, 12, 685-693.

78. Raboudi, K.; Belkaid, A.; Saci, A.B. Satisfaction of the solar bounding box constraints. In Proceedings of the 28th International PLEA Conference, Lima, Peru, 7-9 November 2012.

79. Juyal, M.; Kensek, K.; Knowles, R. SolCAD: 3 D Spatial Design Tool Tool to Generate Solar Envelope. In Proceedings of the 2003 Annual Conference of the Association for Computer Aided Design in Architecture, Indianapolis, IN, USA, 24-27 October 2003.

80. Niemasz, J.; Sargent, J.; Reinhart, C.F. Solar Zoning and Energy in Detached Dwellings. Environ. Plan. B: Urban Anal. City Sci. 2013, 40, 801-813. [CrossRef]

81. De Luca, F. Solar form Finding. In Proceedings of the 37th Annual Conference of the Association for Computer Aided Design in Architecture: Disciplines and Disruption, ACADIA, Cambridge, MA, USA, 2-4 November 2017.

82. De Luca, F.; Dogan, T. A novel solar envelopes method based on solar ordinances for urban planning. Build. Simul. 2019, 12, 817-834. [CrossRef]

83. Darmon, I. Voxel computational morphogenesis in urban context: Proposition and analysis of rules-based generative algorithms considering solar access. In Proceedings of the Conference on Advanced Building Skins, Bern, Switzerland, 26-27 October 2018.

84. Kristl, Ž.; Krainer, A. Site layout as a function of shading in Karst region. In Proceedings of the International Conference "Passive and Low Energy Cooling for the Built Environment, Santorini, Greece, 19-21 May 2005.

85. Kristl, Ž.; Krainer, A. PIRAMIDA, The solar envelope tool. In Proceedings of the TIA Teaching in Architecture Conference, Krems, Austria, 14-15 September 2007. 
86. White, M. Informing an Integrated and Sustainable Urbanism through Rapid, Defragmented Analysis and Design. Ph.D. Thesis, School of Architecture and Design, RMIT University, Melbourne, Australia, 2008.

87. Siret, D.; Houpert, S. A geometrical framework for solving sunlighting problems within CAD systems. Energy Build. 2004, 36, 343-351. [CrossRef]

88. Betti, G.; Arrighi, S. A differential growth approach to solar envelope generation in complex urban environments. In Proceedings of the PLEA 2017 33rd PLEA International Conference-Design to Thrive, Edinburgh, Scotland, 3-5 July 2017.

89. Anderson, K. Design Energy Simulation for Architects; Routledge: New York, NY, USA, 2014.

90. Luque, A.S.; de Luca, F. Solar Toolbox. food4Rhino. 26 October 2019. Available online: https://www. food4rhino.com/app/solar-toolbox (accessed on 10 February 2020).

91. Alkadri, M.F.; Turrin, M.; Sariyildiz, S. The use and potential applications of point clouds in simulation of solar radiation for solar access in urban contexts. Adv. Comput. Des. 2018, 3, 319-338.

92. Koester, R.J. The fundamentals of integrating "the commons": Application as community tissue or urban implant. Renew. Energy 1994, 5, 1015-1020. [CrossRef]

93. Maïzia, M.; Sèze, C.; Berge, S.; Teller, J.; Reiter, S.; Ménard, R. Energy requirements of characteristics urban blocks. In Proceedings of the International Scientific Conference- Renewables in a changing climate-From nanto to urban scale, Lausanne, Switzerland, 2-3 September 2009.

94. Ratti, C.; Morello, E. Sunscapes: Extending the 'solar envelopes' concept through 'iso-solar surfaces'. In Proceedings of the 22nd Conference on Passive and Low Energy Architecture, Beirut, Lebanon, 13-16 November 2005.

95. Ratti, C.; Richens, P. Raster analysis of urban form. Environ. Plan. B: Plan. Des. 2004, 31, 297-309. [CrossRef]

(C) 2020 by the authors. Licensee MDPI, Basel, Switzerland. This article is an open access article distributed under the terms and conditions of the Creative Commons Attribution (CC BY) license (http://creativecommons.org/licenses/by/4.0/). 